\title{
Coronavirus and Carbon Nanotubes: Seeking Immunological Relationships to Discover Immunotherapeutic Possibilities
}

\author{
Elidamar Nunes de Carvalho Lima $\mathbb{D}^{1-3}$, Ana Luiza Moraes Octaviano $\mathbb{D}^{1}$, \\ José Roberto Castilho Piqueira $\mathbb{D}^{1}$, Ricardo Sobhie Diaz $\mathbb{D}^{2}$, João Francisco Justo $\mathbb{D}^{3}$ \\ 'Telecommunication and Control Engineering Department, Polytechnic School of the University of São Paulo, São Paulo, Brazil; ${ }^{2}$ Infectious Diseases \\ Division, Department of Medicine, Federal University of São Paulo, São Paulo, Brazil; ${ }^{3}$ Electronic Systems Engineering Department, Polytechnic School \\ of the University of São Paulo, São Paulo, SP, CEP 05508-0 I0, Brazil \\ Correspondence: Elidamar Nunes de Carvalho Lima, Telecommunication and Control Engineering Department, Polytechnic School of the University \\ of São Paulo, Avenida Prof. Luciano Gualberto - travessa 3 - 158, São Paulo, SP, CEP 05508-0 I0, Brazil, Tel +55 II 309|-5647; +55 II 96326-5550, \\ Email elidamarnunes@usp.br
}

\begin{abstract}
Since December 2019, the world has faced an unprecedented pandemic crisis due to a new coronavirus disease, coronavirus disease-2019 (COVID-19), which has instigated intensive studies on prevention and treatment possibilities. Here, we investigate the relationships between the immune activation induced by three coronaviruses associated with recent outbreaks, with special attention to SARS-CoV-2, the causative agent of COVID-19, and the immune activation induced by carbon nanotubes (CNTs) to understand the points of convergence in immune induction and modulation. Evidence suggests that CNTs are among the most promising materials for use as immunotherapeutic agents. Therefore, this investigation explores new possibilities of effective immunotherapies for COVID-19. This study aimed to raise interest and knowledge about the use of CNTs as immunotherapeutic agents in coronavirus treatment. Thus, we summarize the most important immunological aspects of various coronavirus infections and describe key advances and challenges in using CNTs as immunotherapeutic agents against viral infections and the activation of the immune response induced by CNTs, which can shed light on the immunotherapeutic possibilities of CNTs.
\end{abstract}

Keywords: coronavirus, carbon nanotubes, immunotherapy, immunomodulation

\section{Introduction}

\section{Overview-Coronavirus and Carbon Nanotubes}

The first report of a coronavirus diagnosis was in the 1960s, the virus was obtained from respiratory tract samples of a patient with flu-like symptoms. The coronavirus has been named severe acute respiratory syndrome (SARS-CoV-2), and the disease has been officially named COVID-19 by the WHO. ${ }^{1}$ Coronaviruses are structurally spherical, with a diameter of 80-160 $\mathrm{nm}$ and a large viral RNA of 30kb in size that encodes five proteins: spike (S), membrane (M), envelope (E), glycoprotein hemagglutinin esterase (HE) and nucleocapsid $(\mathrm{N})$. The spike protein $(\mathrm{S})$ is a key protein, determining the specificity of virus-host cell interactions, viral tropism and infectivity. ${ }^{2,3}$

Coronaviruses belong to the family Coronaviridae and are in the Nidovirales order. They have a single-stranded RNA genome and infect various hosts, including humans and other vertebrates, causing respiratory and intestinal infections. ${ }^{4}$ However, these viruses were not considered highly pathogenic to humans until the 2002 outbreak of severe acute respiratory syndrome (SARS) in Foshan, Guangdong, China. ${ }^{5}$ Before this outbreak, coronaviruses that had mainly infected humans caused infections with mild symptoms. For example, the following human coronaviruses (HCoVs) cause mild respiratory diseases HCoV-229E, HCoV-OC43, HCoV-NL63, and HCoV-HKU. ${ }^{6}$ However, SARS-CoV, SARS-CoV-2, and Middle East respiratory syndrome coronavirus (MERS-CoV) are now associated with severe respiratory diseases. ${ }^{5,7}$ 
Comprehension of the immunological aspects involved in each coronavirus outbreak is critical to understanding the immune signaling/activation pathways involved in infection with different types of viruses for efficient management of the public health systems. ${ }^{8,9}$ Recent works on coronaviruses have clarified different aspects of these viruses, such as their infection and immunological processes, pathogenesis, diagnosis, and genomics. ${ }^{10,11}$ However, despite intense research, no studies/research initiatives in the literature have described the details or considerations of the aspects of the relationship between the immune activation caused by coronavirus infections and the immune activation induced by carbon nanotubes (CNTs).

The search for and understanding of immunological relationships between coronaviruses and CNTs, which may be useful in new therapeutic approaches, since CNTs may be immunotherapeutic options for coronavirus infection and useful in research into therapeutic approaches of this type, are rarely described in the literature. ${ }^{12,13}$ Therefore, this study was aimed to explore the relationship between the immune activation of the coronaviruses associated with different outbreaks and the immune activation caused by CNTs, with a focus on discovering potential immunotherapies.

\section{Parameters Considered in This Literature Search}

To develop this study, a systematic review of the literature was performed considering papers published from 1995 to 2021 and using the following electronic databases: PubMed-NCBI, MEDLINE-Bireme, Google Scholar, and ScienceDirect. The main scientific papers were selected using the keywords: "carbon nanotubes" OR "immunotherapy" OR "nanovaccine" OR "coronavirus" OR "viral infection". The inclusion criteria considered in the literature selection for this study included an initial literature review of papers i) containing the exact keywords and, in the subsequent literature review, containing the associated words in the selected texts/abstracts and ii) published in English. As exclusion criteria for this study, we did not consider articles that: i) were not written in English or ii) did not contain the exact and/or associated words cited in the title or abstract of the reference article. The screening of the papers took place independently by two reviewers. A total of 208 articles were included in this final review.

CNTs have been used as agents in preventive and therapeutic strategies against different diseases, including the fight against coronavirus - 2009 (COVID-19). This manuscript includes clinical case articles, review articles, prospective studies focusing on antiviral immunotherapy, especially for coronaviruses, and the use of CNTs as a theranostic agent. Ultimately, these 208 articles were selected and included, based on the relevance of the results and use of nanotechnologies, especially CNTs, to combat viral diseases, particularly those caused by coronaviruses.

\section{Coronaviruses and Immune Response SARS-CoV}

In 2002, China reported its first cases of SARS, which was caused by the emergence of a novel coronavirus, SARS$\mathrm{CoV}^{14}$ This virus begins the replication process after entering the cell by binding to human angiotensin-modifying enzyme receptor 2 (hACE2). ${ }^{7}$ The spike (S) protein of SARS-CoV forms a trimer, with three S1 heads and a trimeric S2 stem, wherein the trimer receptor, named receptor-binding site (RBS), positioned on the tip of every S1 head, binds to the outer surface of hACE2. ${ }^{15}$

Upon entering the respiratory tract, the virus invades epithelial cells, and this infection in addition to viral replication and inflammatory modifications in neighboring cells, contributes to lung tissue damage. ${ }^{16}$ Subsequently, the virus infects immune cells, including $\mathrm{T}$ cells and macrophages, after which the viruses are transported with the aid of antigenpresenting cells-dendritic cells (APC-DCs) to secondary lymphoid organs (Figure 1A). ${ }^{14}$ In this regard, CD8+ T cells account for approximately $80 \%$ of all inflammatory cells infiltrating the lung interstitium, where they participate in the clearance of CoVs in infected cells and induce immune damage. ${ }^{17}$ In contrast, CD4+ T depletion is related to decreased pulmonary recruitment of lymphocytes and increased production of neutralizing antibodies and cytokines, resulting in severe immune-mediated interstitial pneumonitis and delayed clearance of SARS-CoVs from the lungs. ${ }^{9,16}$

In vitro results obtained after viral infection, have demonstrated the occurrence of the production of several cytokines such as C-C motif chemokine ligand 2 (CCL2), CCL3, CCL5, and CX-C chemokine ligand 10 (CXCL10). ${ }^{18}$ These 
cytokines and chemokines are known to recruit immune cells and induce inflammatory injury. In addition, SARS-CoV infection increases the production of macrophages, which produce interferons (IFNs). ${ }^{19}$

The activation and synthesis of these cytokines and chemokines directs the severity of lung injury in SARS-CoV infected patients. Comparative studies have shown elevated levels of proinflammatory cytokines such as IFN- $\gamma$, IL-1, IL6, and IL-12, and chemokines CCL2, CXCL10 and CXCL9 in patients with more severe infections compared to clinically stable patients. Additionally, excess cytokines, known as cytokine storms, play a key role in the progression of the pathogenesis of SARS-CoV infection (Figure 1A). ${ }^{20}$

During the most severe SARS-CoV infection, the immune response is mainly driven mainly by macrophages and neutrophils, but during initial infection, SARS-CoV cannot affect the T-cell response, and because of the continued stimulation caused by the viral infection, these cells induce inflammation to reduce viral replication, which leads to tissue damage. ${ }^{9}$ To inhibit this inflammatory process, a balance must be maintained between the immune response and the production of inflammatory mediators, such as IL-6 and IL-10, which are related to the severity of the disease, as well as tumor necrosis factor (TNF)- $\alpha$, IL-12R, iron protein, and the lymphocytes, neutrophils, eosinophils, and procalcitonin at infection sites. $^{21}$

Pathological examinations of patients with SARS-CoV have shown acute pulmonary edema, extensive infiltration of inflammatory cells, multiorgan failure, thromboembolic complications, and septicemia, which can be caused by cytokine dysregulation. Therefore, increased cytokine levels, such as TNF- $\alpha$, IL-6, and IL-8, may be critical for these unfavorable results. ${ }^{22}$ To elucidate the immune response induced by SARS-CoV, different classes of cytokines and chemokines have been analyzed in patients with SARS-CoV. The levels of IFN- $\gamma$, IL-18, TGF- $\beta$, IL-6, IP10, monocyte chemoattractant protein-1 (MCP-1), MIG, and IL-8 were found to be increased, while those of TNF- $\alpha$, IL-2, IL-4, IL-10, IL-13, and TNFRI were very low or undetectable In addition, the levels of IL-18, IP10, MIG, and MCP-1 in the death group were significantly higher than those in the survivor group, in which IFN $\gamma$ and MCP-1 were inversely proportional to the number of circulating lymphocytes and the number of monocytes (Figure 1A) ${ }^{23}$ In addition, studies show that the bronchoalveolar fluid (BALF) of patients severely infected with COVID-19 has high levels of CCL2- and CCL7-type chemokines, which are essential in recruiting monocytes with chemokine receptor 2-positive (CCR2+). ${ }^{24}$

Testing positive for SARS-CoV is related to the number of circulating neutrophils detected. T-cell-produced chemokines, such as IP10, MIG, and MCP-1, may be critical for the intense inflammation in the lungs of patients who die from SARS-CoV infection, and IFN- $\gamma$-related cytokines induced after SARS coronavirus infection may be critical for the immunopathological damage in these patients. ${ }^{25}$

Studies of SARS-CoV-infected patients have shown a reduction in many kinds of cells, such as leucocytes in $47 \%$, lymphocytes in $84 \%$, and T lymphocytes in $95 \%$ of these patients. ${ }^{11}$ Several cell classes that can be drastically reduced are CD4+ T cells in $100 \%, \mathrm{CD} 8+\mathrm{T}$ cells in $87 \%$ and B-lymphocytes in $76 \%$ of patients, and natural killer (NK) cell levels have decreased by 55\%, which shows that these patients' immune systems are compromised during SARS-CoV infection. In addition, the percentage of CD4 $+\mathrm{T}$ cells is lower than the CD8 $+\mathrm{T}$ cell count. Cellular infiltrates in lung samples obtained from patients by autophagy included macrophages, neutrophils, and CD8+ T cells, in which excessive leukocyte recruitment suggests that chemokines may play a key role in the pathogenesis of SARS-CoV infection. ${ }^{26}$

In vitro results obtained from infected A549 cells showed the production of ligand 2 of C-C chemokine motif/ monocyte chemoattractant protein-1 (CCL2/MCP-1) and CXCL8/IL-8 gene-encoded proteins on the first day after infection. ${ }^{27}$ Therefore, according to these results, monocytes and neutrophils are the first cells recruited to the lungs after SARS-CoV infection, and subsequently, after interaction with SARS-CoV, these recruited macrophages produce chemokines that attract monocytes, neutrophils, and activated $\mathrm{T}$ cells. ${ }^{11}$ Macrophages are targets for SARS-CoV and, consequently, produce chemokines that recruit other cells of the immune system. ${ }^{25}$ In addition, the lung injury caused by the virus may be a result of the accumulation of a many immune system cells and repeated cycles of chemokine production with cellular recruitment. Thus, the inflammatory response can be triggered by the persistent presence of coronavirus in alveolar macrophages and is manifested by an increase in T cells, NK cells, chemokines, and proinflammatory cytokines (Figure 1A). ${ }^{17}$ 


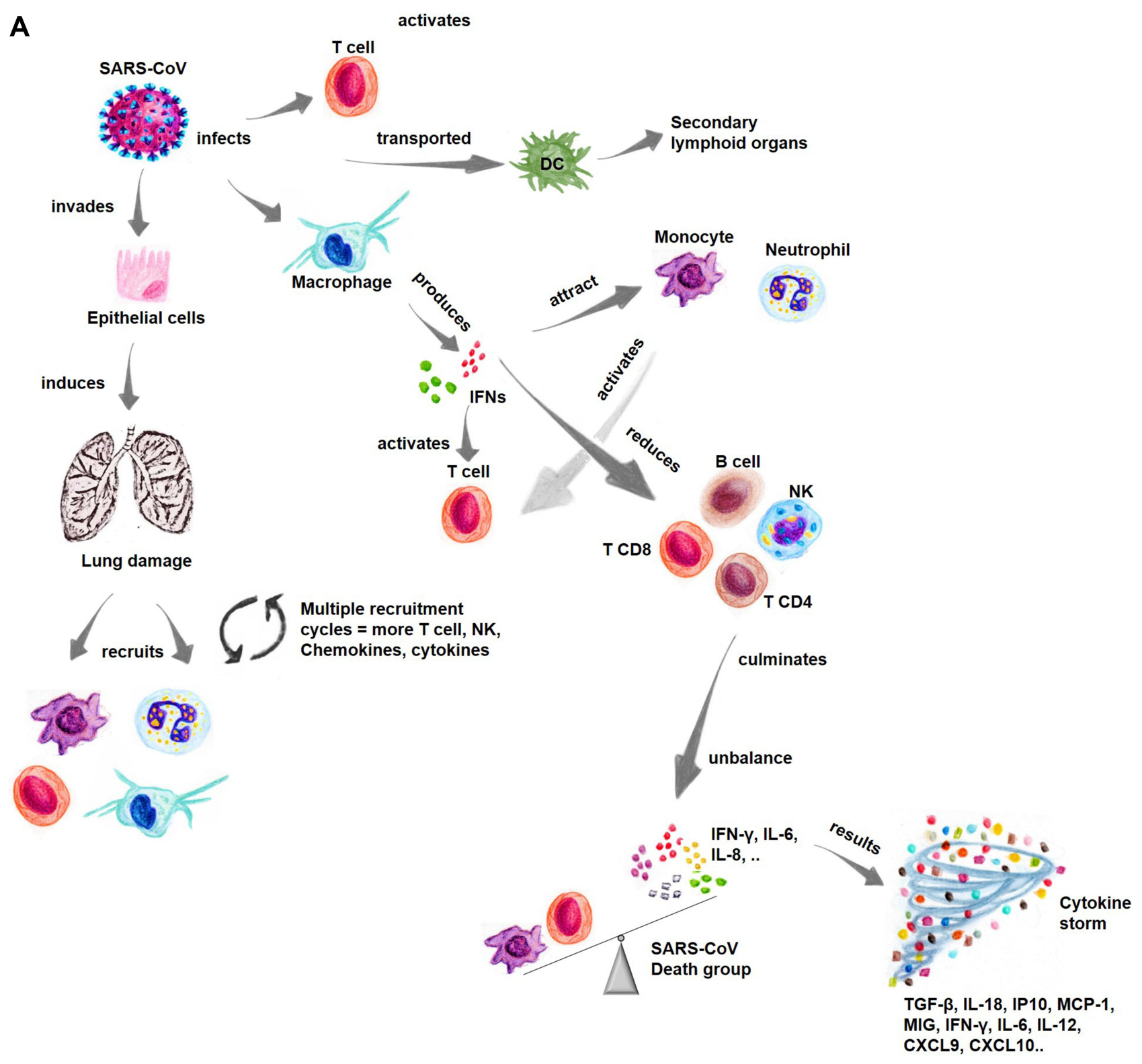

Figure I Continue.

\section{MERS-CoV}

MERS-CoV was first identified in Saudi Arabia in 2012. ${ }^{28}$ The mechanisms of action associated with infection with this virus are similar to those of SARS-CoV infection, in which the S protein of MERS-CoV penetrates the cells through the cell surface dipeptidyl peptidase 4 (DPP4) receptor, promoting the fusion of the virus envelope with the cellular membrane. ${ }^{29}$ The immune response to MERS-CoV is considered severe when the levels of proinflammatory cytokines in the blood are increased, as these cytokines are associated with a large number of neutrophils, macrophages, and few lymphocytes, contributing to the immunopathology. Similar to SARS-CoV patients, patients infected with MERS-CoV present with flu-like symptoms and then develop atypical pneumonia with fever, dry cough, and severe shortness of breath. ${ }^{28}$

After infection with MERS-CoV, common symptoms such as fever and cough may develop into respiratory failure and acute renal failure. Elevated levels of cytokines such as IL-1 $\beta$, IL-6, and IL-8 are common. ${ }^{30}$ MERS-CoV infection 

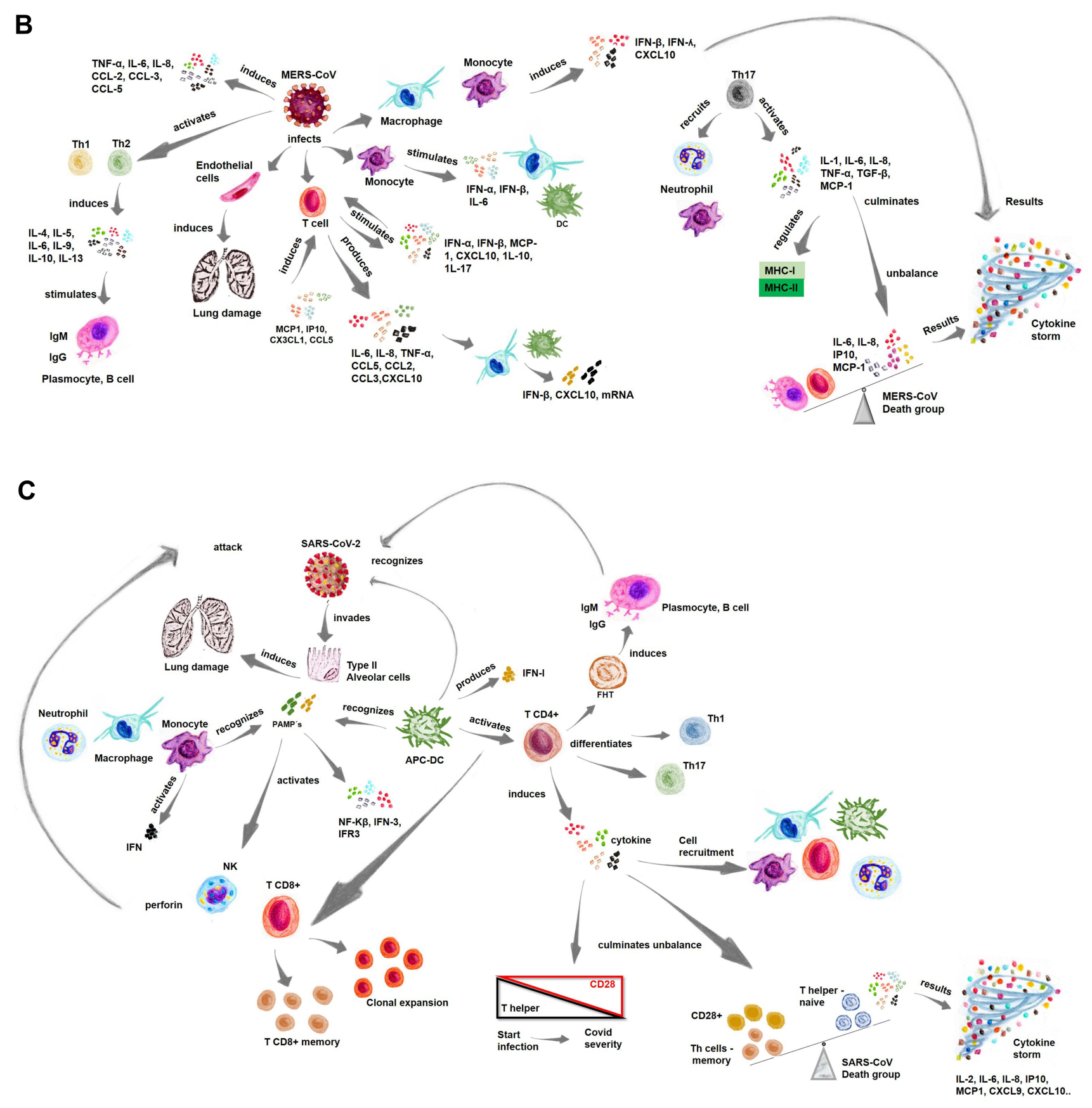

Figure I Immune activation by coronavirus.

Notes: (A-C) The immune response to infections by different coronaviruses, where the different cell types recruited and activated cytokines involved in the inflammatory processes during this infection are shown. Data from references II, I4, 17, 20, 25, 31, 45, and 55.

in macrophages and monocyte-derived DCs potentiates the response of proinflammatory cytokines, including: CCL-2, CCL-3, CCL-5, IL-2 and IL8, which entails a cytokine storm (Figure 1B). ${ }^{20}$

MERS-CoV infects $\mathrm{T}$ cells, inducing apoptosis through the extrinsic and intrinsic pathways. The activation of the replicative rate of MERS-CoV in these immune cells is critical for the high lethality rate of MERS compared to that caused by other coronaviruses. ${ }^{31,32}$ MERS-CoV infection stimulates the production of type I interferons (IFN- $\alpha$ and IFN- $\beta$ ) and the production of chemokines, such as MCP-1, C-X-C motif chemokine ligand 10 (CXCL10), and cytokine IL-10, which are essential for recruiting T cells. ${ }^{27}$ In addition, CD4 helper T cells (Th 1) and NK cells require activation of IL-12 and IFN- $\gamma$ 
signaling because IFN- $\gamma$ expression, together with NK cells and T cells, is involved in the activation of the CD8+ immune response, which is essential for the elimination of viruses. ${ }^{26,32}$

Patients infected with MERS-CoV have increased expression levels of cytokines, especially IL-17, whereby helper $\mathrm{T} 17$ (Th17) cells are involved in the production of proinflammatory cytokines through the signal transducer and activator of transcription 3 (STAT3) and NF-Kb pathways. ${ }^{27}$ These Th17 cells recruit neutrophils and monocytes to the site of inflammation and activate the production of other cytokines, such as IL-1, IL-6, TNF- $\alpha$, TGF- $\beta$, IL- 8 , and MCP- $1 .{ }^{11,25}$ Thus, infection of human airway epithelial (HAE) cells induces the production of proinflammatory cytokines that regulate the major histocompatibility complex (MHC) class I and II molecules. ${ }^{33}$ In addition, MERS-CoV infection induces the continuous production of proinflammatory cytokines and chemokines, such as TNF- $\alpha$, IL- 6 , CXCL10, CCL2, CCL-3, CCL-5, and IL- 8, in dendritic cells and macrophages (Figure 1B). ${ }^{11}$

MERS-CoV can cause increased expression of inflammatory molecules, including IL-12, IFN- $\gamma$, interferon-inducible protein-10 (IP10) CXCL10, MCP-1/CCL-2, MIP1 $\alpha /$ CCL-3, RANTES/CCL-5, and IL- $8 .{ }^{33}$ In addition, the induction of cytokines/chemokines that recruit immune cells can cause a large number of immune cells to enter the lower airways, causing inflammation and tissue damage. ${ }^{22}$ Cytokines such as IFN- $\gamma$, TNF- $\alpha$, TNF- $\beta$, and IL-2 play crucial roles in antiviral immunity by increasing the cytotoxic effects of CD8+ T cells and stimulating NK cells, which help regulate cellular immunity. Helper T2 (Th2) cells secrete IL-4, IL-5, IL-6, IL-9, IL-10, and IL-13, which mediate the humoral immune response and stimulate antibody production. ${ }^{25}$ Then, the high expression of inflammatory cytokines and the negative regulation of Th1 and Th2 immune responses in the lower airways of MERS-CoV-infected patients lead to more severe infection, lung inflammation, and immunopathological changes with higher mortality rates. ${ }^{33}$

MERS-CoV infection activates a proinflammatory Th1 and Th17 cytokine profile. ${ }^{25}$ Patients develop serum IgG and IgA responses in the respiratory tract, and chemokines, such as MCP-1, IP10, CX3CL1, and CCL5, are elevated, which can induce T-lymphocyte recruitment and contribute to cell-mediated antiviral responses in inflamed tissues. ${ }^{16}$ In addition, the levels of cytokines such as IL-10, IL-15, TGF- $\beta$, and EGF, correlate with disease severity, and the intense induction of various chemokines, such as IL-8, IP10, MIP1, and CCL5, has led to the kinetics in patients who have recovered from pneumonia that differ from those in patients with mild disease. ${ }^{25}$

The response to MERS-CoV invasion of macrophages and monocyte-derived dendritic cells (MDDCs) induces IFN$\beta$, IFN- $\lambda 1$, CXCL10, and MxA mRNA expression, while almost no induction is observed in response to SARS-CoV infection. ${ }^{34}$ Therefore, the replication capacity of MERS-CoV is restricted to human leukocytes, but viral replication can induce a detectable IFN-mediated antiviral response; both SARS-CoV and MERS-CoV replicate weakly in human macrophages and MDDCs. Clinical disease and histopathological changes are more severe in the absence of type I IFN signaling, and a T-cell response is required for viral clearance. ${ }^{27}$

Another study showed that MERS-CoV can replicate in monocyte-derived macrophages (MDMs), thereby significantly stimulating the expression of antiviral cytokines such as IFN $\alpha$, IFN $\beta$, TNF- $\alpha$, and IL-6. Compared with SARSCoV, MERS-CoV can induce significantly higher expression of IL-12 and IFN $\gamma$ and chemokines such as IP10/CXCL10, MCP-1/CCL2, MIP1 $\alpha / C C L 3$, CCL5, and IL- $8 .{ }^{35}$ The expression of MHC-1 is higher in MERS-CoV-infected cells than in SARS-CoV-infected cells, demonstrating that MERS-CoV can infect human macrophages and induce excessive inflammatory cytokine and chemokine responses that contribute to the pathogenesis of these diseases. ${ }^{33}$ MERS-CoV also infects vascular endothelial cells in the pulmonary interstitium, which elevates the number of immune system cells that infiltrate the patient's lower respiratory tract, causing inflammation and tissue damage. ${ }^{36}$

High concentrations of IP10, MCP-1, and IL-6 are closely associated with the mortality of MERS-CoV-infected persons, while low antibody levels demonstrate a trend toward mortality (Figure 1B). ${ }^{33}$ In patients with severe pneumonia, antibodies can be detected within 18 months of infection, while patients with upper respiratory tract disease or no clinical symptoms show no detectable antibody response to MERS-CoV challenge. Therefore, antibody longevity is variable in patients with milder disease, indicating a correlation with disease severity. ${ }^{10}$ Thus, consistent with the findings in previous studies, specific antibody levels are significantly related to the severity of clinical symptoms and the duration of maximum viral persistence. ${ }^{37}$ 


\section{SARS-CoV-2}

A novel coronavirus (SARS-CoV-2) that causes SARS emerged in Wuhan, China, in December $2019 .{ }^{14}$ The World Health Organization (WHO) declared a global public health emergency due to the prevalence of COVID-19. The genomic structures of SARS-CoV, MERS-CoV, and SARS-CoV-2 are similar. The major proteins are the structural proteins $\mathrm{S}, \mathrm{E}, \mathrm{M}$, and N; the accessory proteins; and the nonstructural proteins (NSPs, eg NSP-16). However, these viruses rely on the spike (S) protein to recognize cellular targets and bind with cell membranes. ${ }^{3,16}$

The S protein, which is critical for virus linking to the membrane cell host, is composed of S1 and S2 subunits, with the S1 subunit containing an N-terminal domain (NTD) and a C domain, which carries a receptor-binding domain (RBD). ${ }^{38}$ Although SARS-CoV recognizes only ACE2, SARS-CoV-2 recognizes both ACE2 and CD147, and MERS$\mathrm{CoV}$ recognizes only DPP4. These binding site preferences are the result of differences between the accessory subdomains in SARS-CoV, SARS-CoV-2 and MERS-CoV. ${ }^{39}$

For SARS-CoV-2, the cell entry process is dependent on transmembrane serine protease 2 (TMPRSS2), which is critical for cleaving the viral S protein into two subunits: S1 and S2. The S2 subunit fuses the virus and cell membranes, and the $\mathrm{S} 1$ subunit consists of an amino-terminal domain and an RBD, which binds to ACE2 and initiates the infection process. ${ }^{40}$ This binding triggers endocytosis of the SARS-CoV-2 virus and exposes it to endosomal proteases. The S2 subunit consists of a fusion peptide (FP) region and two heptad repeat regions: HR1 and HR2. ${ }^{41}$ Within the endosome, the S1 subunit is cleaved, exposing the FP, which inserts into the host membrane; subsequently, this S2 region folds in on itself to bring the HR1 and HR2 regions together causing fusion with the membrane and release of the viral package into the host cytoplasm. ${ }^{3}$ Clearly, the immune response produced by SARS-CoV-2 is initiated after the virus binds to the receptor ACE2, which is mainly expressed on type II alveolar cells in the lung (Figure 1C). ${ }^{31}$

Innate immune cells recognize the invasion of the virus through the expression of pathogen-associated molecular patterns (PAMPs), and the immune response is then initiated. In the case of coronaviruses, PAMPs are genomic RNAs, including double-stranded RNA (dsRNA), or intermediates formed during viral replication. ${ }^{3}$ PAMPs are recognized by the endosomal RNAs of Toll-like receptors (TLRs), such as TLR3, TLR7, TLR8, and cytosolic RNA sensors. ${ }^{42}$ In addition to recognizing PAMPs, TLRs in human CD14+ monocytes activate different signaling pathways related to type I IFN and secretion of cytokines involved in CD4+ T-cell polarization. Furthermore, recognition of PAMPs leads to activation of signaling cascades, such as the nuclear factor $\kappa B(N F-\kappa B)$ and IFN-3 regulatory factor (IRF3) pathways (Figure 1C). ${ }^{43}$

In nuclei, these transcription factors induce the expression of type I IFN and other proinflammatory cytokines. These initial responses are the first line of defense against viral infection at the site of entry. Once the virus is inside tissue cells, viral peptides are presented to cytotoxic CD8+ T cells via major MHC class I proteins. All these results show the direct relationship between the severity of infection caused by SARS-CoV-2 and excess cytokines, called cytokine storm (Figure 1C). Severely infected SARS-CoV-2 patients have significantly higher levels of cytokines such as IL-2, IL-7, IL10 , G-CSF, IP10, MCP1, MIP1 $\alpha$, and TNF- $\alpha .{ }^{20}$

During peptide presentation, $\mathrm{CD} 8+\mathrm{T}$ cells are activated and begin to divide and exhibit clonal expansion, developing virus-specific effector and memory T cells. ${ }^{33}$ In addition, cytotoxic CD8+ T cells and NK cells lyse virus-infected tissue cells (via perforins and granzymes), and within a short time, professional APCs (mainly subepithelial dendritic cells and tissue macrophages) recognize whole viruses and viral particles and present viral peptides to CD4+ T cells via Class II MHC molecules. ${ }^{44}$ Thus, CD4+ T cells are induced by APCs to differentiate into Th1, Th17, and memory follicular helper T (FHT) cells. These FH-T cells facilitate B-cell development into plasma cells (PCs), which stimulates the production of virus-specific antibodies such as IgM, IgA, and IgG. In addition, B cells can directly recognize viruses and be activated by them (Figure 1C). ${ }^{45}$

$\mathrm{CD} 8+\mathrm{T}$ cells are crucial for directly attacking and killing virus-infected cells, while CD4+ $\mathrm{T}$ cells are essential for inducing CD8+ T cells and B cells and producing cytokines, which drive immune cell recruitment. ${ }^{26}$ In addition, DCs are important immune response cells that can effectively stimulate $\mathrm{T}$ and B-lymphocyte activation, thereby promoting innate and adaptive immunity. ${ }^{44}$ Immature DCs show great capacity to migrate and can activate $\mathrm{T}$ cells at a central start site, 
regulating and supporting the immune response. In addition, plasmacytoid DCs (pDCs) comprise a subset of DCs that are characterized by their ability to produce large amounts of antiviral type I interferon (IFN-I). ${ }^{27}$

The stimulation of SARS-CoV-2-specific T cells and memory B cells may induce long-term protection, although long-term protection still needs to be confirmed. ${ }^{44,46}$ The immune response is coordinated by FHT cells, indicators that the humoral immune response has matured, and specific memory B cells are ready to respond quickly to reinfection. SARS-CoV-2-specific $\mathrm{T}$ cells are recruited from preconstituted $\mathrm{T}$ cells that can recognize specific viral epitopes. ${ }^{43}$ However, the frequency and severity of reinfection by SARS-CoV-2 remain unclear. ${ }^{47}$

In addition, $\mathrm{CD} 4+$ specific $\mathrm{T}$ cells play an important role in inducing the $\mathrm{B}$ cell response that leads to antibody affinity maturation. ${ }^{10}$ The number of specific $\mathrm{T}$ lymphocytes produced is correlated with serum IgG and IgA titers. Naive T cells and memory T cells are important immune components, and their balance is essential for maintaining an effective defense response. Naive T cells defend against unknown infections through increased and coordinated cytokine release, while memory $\mathrm{T}$ cells Control the antigen-specific immune response. ${ }^{25}$

Compared to regulatory $\mathrm{T}$ cells, the downregulation favors the activity of naive $\mathrm{T}$ cells and can strongly contribute to hyperinflammation. On the other hand, according to case reports on reinfection, a reduction in memory $\mathrm{T}$ cells may cause recurrence of COVID-19. ${ }^{10}$ Regulatory $\mathrm{T}$ cells are critical for maintaining immune homeostasis by inhibiting the activation, proliferation, and proinflammatory function of most lymphocytes, including CD4+ T cells, CD8 $+\mathrm{T}$ cells, NK cells, and B cells. ${ }^{9}$

In severe COVID-19 infection, the percentage of naive $\mathrm{T}$ helper cells increases, while the percentage of memory helper $\mathrm{T}$ cells and CD28+ cytotoxic suppressor $\mathrm{T}$ cells decreases. ${ }^{48}$ The balance between naive $\mathrm{T}$ cells and memory $\mathrm{T}$ cells is essential to mediate an effective immune response. ${ }^{49}$ In addition, the helper CD4+ $\mathrm{T}$ cells are critical for optimal antibody responses and the activation of CD8 $+\mathrm{T}$ cells in host defense. When neutralizing antibody-mediated protection is incomplete, cytotoxic CD8+ T cells are particularly important for viral elimination. ${ }^{36}$

According to another study, 100\% of people who recovered from COVID-19 had S protein-specific CD4+ T cells and $70 \%$ had S protein-specific CD8+ T cells in their blood circulation. ${ }^{50}$ The incubation period of SARS-CoV-2 infection that extends from 2 to 12 days, also called the presymptomatic period, is associated with virus-mediated innate immunosuppression and delayed activation of $\mathrm{T}$ cells, especially CD8+ T cells, as shown in SARS-CoV and MERSCoV. In COVID-19 patients, the CD4:CD8 ratio is equal to 2:1 (normal value), indicating no significant difference compared to the control group. ${ }^{51}$

The expression of CD8 in cytotoxic T lymphocytes (CTLs) in infected patients increases significantly, demonstrating that the immune response to COVID-19 infection occurs through overexpression of CD8 and hyperactivation of CTL antiviral responses and not through changes in the CD8 and CD4 ratio. ${ }^{51,52}$ Compared with those of patients outside the intensive care unit, the cytokine and chemokine responses of COVID-19 pneumonia patients in intensive care show abnormal chest tomography results. ${ }^{53}$ Infected patients in intensive care have higher plasma levels of cytokines, such as IL-2, IL-7, IL-10, GSCF, IP10, MCP-1, MIP1A, and TNF- $\alpha$ (Figure 1C). ${ }^{25}$

Patients with severe infection also have elevated levels of inflammatory cytokines, mainly IL-8, IL-6, and IL-1 $\beta$, in their bronchoalveolar lavage fluid (BALF) compared to the levels in patients with moderate infection. ${ }^{54}$ Compared with those of healthy people, the expression levels of CXCL9, CXCL10, and CXCL11 are elevated in all patients with COVID-19, but CXCL16 is more highly expressed in patients with moderate infection than in those with severe infection (Figure 1C). ${ }^{55}$

Hence, lung macrophages in patients with severe COVID-19 contribute to local inflammation by recruiting inflammatory monocytic cells and neutrophils through CCR1 and CXCR2 activation, while macrophages in patients with moderate COVID-19 infection produce more chemokines that attract $\mathrm{T}$ cells through the involvement of CXCR3 and CXCR6. ${ }^{50,55}$ Additionally, the secretion of cytokines, including TNF- $\alpha$, IL-6, and IL-10, is increased in the patients with severe disease, and the numbers of CD4+ T cells and CD8+ T cells are negatively correlated with TNF- $\alpha$, IL- 6 , and IL-10 levels, suggesting that these cytokines may be involved in the decrease in T cells detected in COVID-19 infection. ${ }^{25}$ 


\section{Immune Evasion of Coronaviruses}

Similar to most well-adapted viruses, coronaviruses have developed strategies to bypass the innate immune response. ${ }^{56,57}$ Type 1 interferon (IFN) expression is crucial for the initial host response. ${ }^{43}$ The innate immune system recognizes dsRNA through activation of cytosolic (RIG-1 and MDA-5) and membranous (TLR3) pattern recognition receptors (PRRs). Recognition by these PRRs triggers the activation of IFN regulatory factors (IRF3 and IRF7), which leads to the induction of type 1 IFNs, such as IFN $\alpha$ and IFN $\beta .{ }^{27}$ Type 1 IFNs activates immune antiviral effectors, such as NK cells, $\mathrm{CD} 8+\mathrm{T}$ cells, and macrophages, allowing viral clearance. In this regard, previous studies have shown that SARS-CoV proteins contribute to IFN signaling to evade innate immunity and prevent viral clearance. ${ }^{55}$

The acute phase of the immune response to SARS-CoV or SARS-CoV-2 infection can cause lymphopenia and a decrease in lymphocytes. ${ }^{58}$ In this regard, IFN-I inhibition, which weakens DC activation and activation processes, contributes to T-cell differentiation and expansion. ${ }^{31}$ An efficient type I IFN response can abrogate viral replication and early spread, but in SARS-CoV and MERS-CoV infections the type I IFN response to viral infection is suppressed, and both of these coronaviruses interfere with the signal transduction that triggers type I IFN production. ${ }^{27}$ Specifically, during the type I IFN induction step, SARS-CoV interferes with RNA sensor signaling, including ubiquitination and degradation of RNA adaptor molecules, such as MAVS and TRAF3/6, by inhibiting IRF3 nuclear translocation. ${ }^{59}$ In addition, MERS-CoV expresses proteins that interfere with IFN signaling and proteins, such as ORF4a, ORF4b, and ORF5, inhibiting both type I IFN induction and repressing NF- $\mathrm{KB}$ signaling pathways, contributing to the evasion of innate immunity. ${ }^{60}$

MERS-CoV also represses histone modification. ${ }^{61}$ Both SARS-CoV and MERS-CoV inhibit IFN signaling through mechanisms such as inhibiting STAT1 phosphorylation, and the viral proteins involved in regulating this host type I IFN response are structural proteins, such as the $\mathrm{M}, \mathrm{N}$ and nonstructural ORF proteins. ${ }^{62}$ Therefore, because it suppresses NK cell, macrophage, and CD8+ T-cell activation, viral inhibition of IFN signaling inhibits the innate immune response and enables viral persistence. This effect may be associated with excessive cytokine production, which leads to a constant proinflammatory state through the synthesis of cytokines such as IL-1, IL-6, IL-8, IL-21, tumor necrosis factor-beta (TNF- $\beta$ ), and MCP-1, worsening respiratory performance. ${ }^{22,43}$

\section{Immune Activation by Carbon Nanotubes}

CNTs are cylindrical structures classified according to the number of walls that compose them: single-walled carbon nanotubes (SWCNTs) or multiwalled carbon nanotubes (MWCNTs) ${ }^{63}$ CNTs have an approximate diameter of 0.4-2 nm (SWCNTs) or 10-100 nm (MWCNTs), and both types of CNTs can be used in biological/biomedical systems. ${ }^{64}$ However, the size, diameter, and chirality of CNTs play important roles in their biological applications. ${ }^{65}$

The development of nanotechnological CNT bioproducts is based on the physical-chemical properties of CNTs, allowing their safe use in applications. Creating and developing new nanobiotechnological products are urgent endeavors when the goal is to provide new types of immunotherapies that generate and/or improve an immune response. ${ }^{12,66,67}$ Therefore, the safety and development of new materials used to restore and modulate the immunological systems in patients affected by several diseases/infections are realities. ${ }^{68}$

Nanomaterials have been widely used in immunotherapies for immunomodulation. ${ }^{69}$ Studies show what are the main aspects related to CNTs entry into the cell, its toxicity and intracellular elimination mechanisms, as well as means of functionalization in relation to use in therapy as a drug delivery system and especially immunotherapy. ${ }^{63}$ These immunomodulatory effects suggest the possibility of manipulating different properties of nanomaterials, especially those related to size and functionalization. Hence, it is essential to understand the interactions of nanomaterials with the immune system, which will be useful and fundamental for the development of specific strategies for creating immunotherapies against different infectious and noninfectious diseases. ${ }^{70,71}$

Previous studies have shown that functionalization of CNTs alters the recognition and profiles of APC-DCs. ${ }^{72}$ Functionalized CNTs (f-CNTs) with anionic phospholipids change not only the recognition but also uptake by phagocytic cells. In another essential feature of CNTs, DCs can internalize CNTs without compromising cell integrity. ${ }^{73}$ The effect of CNTs on lymphocyte cells is related not only to CNT physicochemical properties but also to CNT morphology and the 
type of functionalization. Although CNTs do not affect cytokine expression, they can induce TNF- $\alpha /$ IL-12/IL-6 and IL-2/ IFN $\gamma$ activation in a dose-dependent manner. ${ }^{74}$ In this sense, CNTs functionalized upon 1,3-dipolar cycloaddition do not induce toxicity in murine $\mathrm{T}$ or $\mathrm{B}$ cells and stimulate cell lines more efficiently when associated with specific molecules such as CD3. ${ }^{67}$

CNTs associated with molecules applied in immunotherapeutic systems have been used to enhance/alter the immunological responses through cells induced by the innate immune system, such as monocytes/macrophages. This enhanced response results in the secretion of proinflammatory cytokines and $\mathrm{T}$ cell stimuli. Nonfunctionalized CNTs, named pristine CNTs (PCNTs), are toxic and inviable for biological/biomedical use. ${ }^{75,76}$ For CNTs to be used in biological/biomedical systems, different factors need to be considered, including CNT physicochemical characteristics, size, surface charge, hydrophobicity, surface topography, and material composition, which can be specified to modify and facilitate immune system interactions. ${ }^{77}$

The complement system allows the recognition of abnormal components including synthetic materials; harmful microorganisms; cellular alterations, such as apoptosis and necrosis; and aggregated proteins. In addition, the activation mechanisms of the complement system can be mediated by classical, alternative, and lectin pathway induction, which is triggered when molecules are targeted for elimination via the formation of the membrane attack complex (MAC). ${ }^{78,79}$

CNT functionalization and PEGylation can interfere with the recognition of abnormalities by the complement system. ${ }^{80}$ In this regard, the complement system may be activated according to the type of CNT functionalization, eg, CNTs functionalized with albumin induce classic and alternative pathway activations through a C1-q-mediated mechanism, with the classical pathway being the predominant pathway activated. ${ }^{81}$ The differences in complement system activation are mainly related to the degree of CNT functionalization and the chemical nature of the substances involved in this functionalization. ${ }^{82}$

\section{Immunological Relations: Coronavirus vs Carbon Nanotubes}

The three coronaviruses causing the most recent outbreaks have exerted impacts on the immune system. For example, SARS-CoV avoids detection by cellular PRRs by secreting viral dsRNA. ${ }^{83}$ In contrast, MERS-CoV stimulates an increase in cytokines produced by macrophages, DCs, and T cells. SARS-CoV-2, on the other hand, causes an increase in monocytes, eosinophils, neutrophils, cytokines, chemokines, and macrophages derived from CD14+ CD16+ monocytes (Table 1). ${ }^{8,84}$

Concerning to T cells, SARS-CoV induces CD4+ and CD8+ memory T-cells responses for between 3 months and 6 years. In MERS-CoV samples, T-cell responses have been detected for as many as 11 years after the initial illness. ${ }^{85}$ Furthermore, viral M, N, and S proteins are the main structural targets of host cells exposed to coronaviruses, including SARS-CoV-2. ${ }^{38,86}$

In combating SARS-CoV, antibodies bind to the S1 RBD to block the interaction of the RBD with host ACE2 and can also bind other regions of S1 and S2 to inhibit protein S conformational changes and membrane fusion. The duration of antibody effects varies according to the severity of the disease. In MERS-CoV, IgM and IgG levels increase in the first week, but shortly thereafter, the IgM level gradually decrease. Similarly, in SARS-CoV-2, specific IgM and IgG are detectable within 1-2 weeks after symptoms appear. ${ }^{87,88}$

CNTs can also stimulate some pathways in the immune system. An example of these monocyte-activating CNTs (MA-CNTs) is their ability to positively regulate the molecular pathways involving the IL-6, CD-40, dendritic cell maturation, TNF- $\alpha /$ TNF receptor (R) $1-2$, and NF-kB and T-h 1 chemokine signaling pathways (CXCR3 and CCR5 linker pathways) (Figure 2). These pathways are commonly activated during acute inflammatory processes, such as those associated with immune-mediated tumor rejection and pathogen clearance. ${ }^{25}$

Furthermore, NK cells can be stimulated by f-MWCNTs, and those with a smaller diameter are more efficiently internalized into peripheral blood mononuclear cells (PBMCs). ${ }^{43,86}$ When CNTs encounter the immune system, they can interact with components of this system and with soluble plasma proteins, forming a coronal structure around them, which can alter their interaction with cells of the complement system. ${ }^{89}$ Some opsonins that make up this coronal structure can increase the uptake of these components by macrophages and other cells. Complement proteins (complement protein $\mathrm{C} 1 \mathrm{q}$, mannose-binding lectin (MBL), and C-reactive protein) can recognize the surface of f-CNTs 
Table I Comparison of Immune Characteristics of the Three Recent Coronavirus Outbreaks and CNTs

\begin{tabular}{|c|c|c|c|c|}
\hline $\begin{array}{l}\text { General } \\
\text { Aspects }\end{array}$ & SARS-CoV & MERS-CoV & SARS-CoV-2 & CNTs \\
\hline Genus & Betacoronavirus $^{85}$ & Betacoronavirus $^{85}$ & Betacoronavirus $^{85}$ & - \\
\hline Mortality & $9.6 \%^{89}$ & $34.4 \%^{89}$ & Estimated in $2 \%^{89}$ & - \\
\hline $\begin{array}{l}\text { Year of } \\
\text { origin }\end{array}$ & $2002^{8}$ & $2012^{8}$ & $2019^{8}$ & $1991^{64}$ \\
\hline Receptor & $\mathrm{ACE}^{39}$ & DPP4 ${ }^{39}$ & ACE2 ${ }^{39}$ & $\begin{array}{l}\text { They show the ability to bind } \\
\text { to the active protease site of } \\
\text { HIV, blocking its function. }{ }^{87}\end{array}$ \\
\hline Cells target & $\begin{array}{c}\text { Airway epithelial ciliated } \\
\text { cells and type } 2 \text { alveolar } \\
\text { pneumocytes. }^{88}\end{array}$ & $\begin{array}{l}\text { Pneumocytes and syncytial } \\
\text { epithelial cells. }^{88}\end{array}$ & $\begin{array}{l}\text { Cells with receptor ACE2, } \\
\text { especially airway epithelial } \\
\text { ciliated cells, and type } 2 \\
\text { alveolar pneumocytes. }^{88}\end{array}$ & $\begin{array}{l}\text { Potentially macrophages, NK } \\
\text { cells, monocytes, DCs, T cells, } \\
\text { and components of the } \\
\text { complement system. } .^{92,190}\end{array}$ \\
\hline $\begin{array}{l}\text { Main } \\
\text { cytokines } \\
\text { and } \\
\text { chemokines } \\
\text { secreted }\end{array}$ & $\begin{array}{l}\text { IL-I, TNF- } \alpha, \text { IL-6, IFN- } \alpha / \gamma, \\
\text { CCL2, CCL3, CCL5, } \\
\text { CXCLI0, IL-8; IFN type I, } \\
\text { and Type II. }{ }^{44}\end{array}$ & $\begin{array}{c}\text { IFN- } \alpha / \gamma, \text { IL-6, IL-8, IL-I2, IL-I } \beta \text {, } \\
\text { TNF- } \alpha \text {, IL-6, CXCLI0, CCL-2/ } \\
\quad 3 \text { and } 5 \text { and IL- } 8 .{ }^{89}\end{array}$ & $\begin{array}{l}\text { IL-6, TNF- } \alpha, \text { MIPI- } \alpha, \text { MCP-3, } \\
\text { GM-CSF, IL-2, IFN type I and } \\
\text { type II, IPI0, CCL2, CXCLI, } \\
\text { and CXCL5. }{ }^{26}\end{array}$ & $\begin{array}{l}\text { DWNTs induced IL-I } \beta \text { linked } \\
\text { to caspase-I and activation of } \\
\text { the NLRP } 3 \text { inflammasome; } \\
\text { f-MWCNTs induced the } \\
\text { expression of CD25 activation } \\
\text { markers and release of IL-I } \beta \text {, } \\
\text { IL-6, TNF, and IL-I0 by CDI4 } \\
\quad+\text { monocytes not } \\
\text { accompanied by the activation } \\
\text { of cytotoxic mechanisms. } \\
\text { f-CNTs activated molecular } \\
\text { pathways, such as the Toll-like } \\
\text { receptor (TLR). }{ }^{91,207}\end{array}$ \\
\hline $\begin{array}{l}\text { Impacts on } \\
\text { the immune } \\
\text { system }\end{array}$ & $\begin{array}{l}\text { Viral proteins antagonize the } \\
\text { IFN response, induce T cell } \\
\text { apoptosis, and delay T cells } \\
\text { response, especially that of } \\
\text { CD8+ T cells. }\end{array}$ & $\begin{array}{l}\text { Suppresses of the innate } \\
\text { immune system and } \\
\text { interferons; induces apoptosis } \\
\text { of CD4+ and CD8+ T cells; } \\
\text { increases cytokines levels in } \\
\text { macrophages, DCs, and } \\
\text { T cells. }{ }^{89,207}\end{array}$ & $\begin{array}{l}\text { Bypasses the innate immune } \\
\text { system and interferon antiviral } \\
\text { response; delay T-cell } \\
\text { responses (particularly CD8+ } \\
\text { T cells); decreases DCs and } \\
\text { NK cells in severe cases. }{ }^{26,60}\end{array}$ & $\begin{array}{l}\text { Can interact with components } \\
\text { of the immune system and } \\
\text { with soluble plasma proteins } \\
\text { to form a coronal structure } \\
\text { around them, altering their } \\
\text { interaction with cells in the } \\
\text { complement system. } \\
\text { Complement proteins (Clq, } \\
\text { MBL and C-reactive protein) } \\
\text { can recognize the surface of } \\
\text { functionalized CNTs. }{ }^{79,91}\end{array}$ \\
\hline $\mathrm{T}$ cells & $\begin{array}{c}\text { Produce pro-inflammatory } \\
\text { cytokines via the NF-kB } \\
\text { pathway. }{ }^{208}\end{array}$ & $\begin{array}{c}\text { CD8+ T-cell responses can be } \\
\text { detected without antibody } \\
\text { responses. }{ }^{208}\end{array}$ & $\begin{array}{l}\text { CD4+ T cells increase anti- } \\
\text { S-RBD IgG and IgA. CD8+ } \\
\text { T cells eliminate the virus } \\
\text { when antibody action is } \\
\text { reduced. Decreases of } \\
\text { regulatory and memory T cells } \\
\text { lead to increases in } \\
\text { cytokines. }^{208}\end{array}$ & $\begin{array}{l}\text { Deliver siRNA for efficient } \\
\text { RNAi of CXCR4 and CD4 } \\
\text { receptors in human T cells and } \\
\text { peripheral blood mononuclear } \\
\text { cells (PBMCs). }{ }^{94}\end{array}$ \\
\hline
\end{tabular}

(Continued) 
Table I (Continued).

\begin{tabular}{|c|c|c|c|c|}
\hline $\begin{array}{l}\text { General } \\
\text { Aspects }\end{array}$ & SARS-CoV & MERS-CoV & SARS-CoV-2 & CNTs \\
\hline Antibodies & $\begin{array}{l}\text { Specific to the RBD domain } \\
\text { of protein S. Decrease after } \\
\qquad \mathrm{I} / 2 \text { year. }^{208}\end{array}$ & $\begin{array}{l}\text { Strong affinity for the spike } \\
\text { protein. They facilitate viral } \\
\text { entry by antibody-dependent } \\
\text { potentiation (ADE). IgM and } \\
\text { IgG levels are increased in the } \\
\text { first week. IgM level gradually } \\
\text { decreases. No detection after } \\
6 \text { years. }^{208}\end{array}$ & $\begin{array}{l}\text { The main target is protein } \mathrm{S} \text {, } \\
\text { but there are antibodies } \\
\text { against nucleocapsid protein } \\
\text { (N). Persistence is uncertain, } \\
\text { with decreases observed } \\
\text { months later. }\end{array}$ & $\begin{array}{l}\text { Bind to the B cell epitope and, } \\
\text { increase the amount of } \\
\text { antibody-producing B cells to } \\
\text { modulate the immune } \\
\text { response. }{ }^{93,119}\end{array}$ \\
\hline
\end{tabular}

(Figure 2). Furthermore, NK cells can also be stimulated by f-MWCNTs, and those with a small diameter are more efficiently internalized by PBMCs. ${ }^{78,90}$

In the generation of antibodies, SWCNTs are effective as antibodies against the CD3 complex of T cells, as determined by the presentation of high-density immobilized protein stimuli induced through a chemical treatment method. SWCNTs have also been used with short interfering RNA (siRNA) in human T cells and primary cells, delivering siRNA to cause efficient RNA interference (RNAi) of CXCR4 and CD4 receptors on human T cells and PBMCs. They also show antibody-like responses when bound to a foot-and-mouth disease virus (FMDV) B-cell epitope, when bound to a template pentapeptide or an antigenic epitope, and when bound to dengue virus serotype 3 recombinant envelope proteins. ${ }^{78,91,92}$

\section{Advances in the Use of Carbon Nanotubes as Immunotherapeutic Agents CNTs as Immunotherapeutic Agents}

CNTs interact with immune system components and soluble plasma proteins, forming a coronal structure around the nanotubes and changing the nature of coronal-enveloped cell and complement system component interactions. ${ }^{78}$

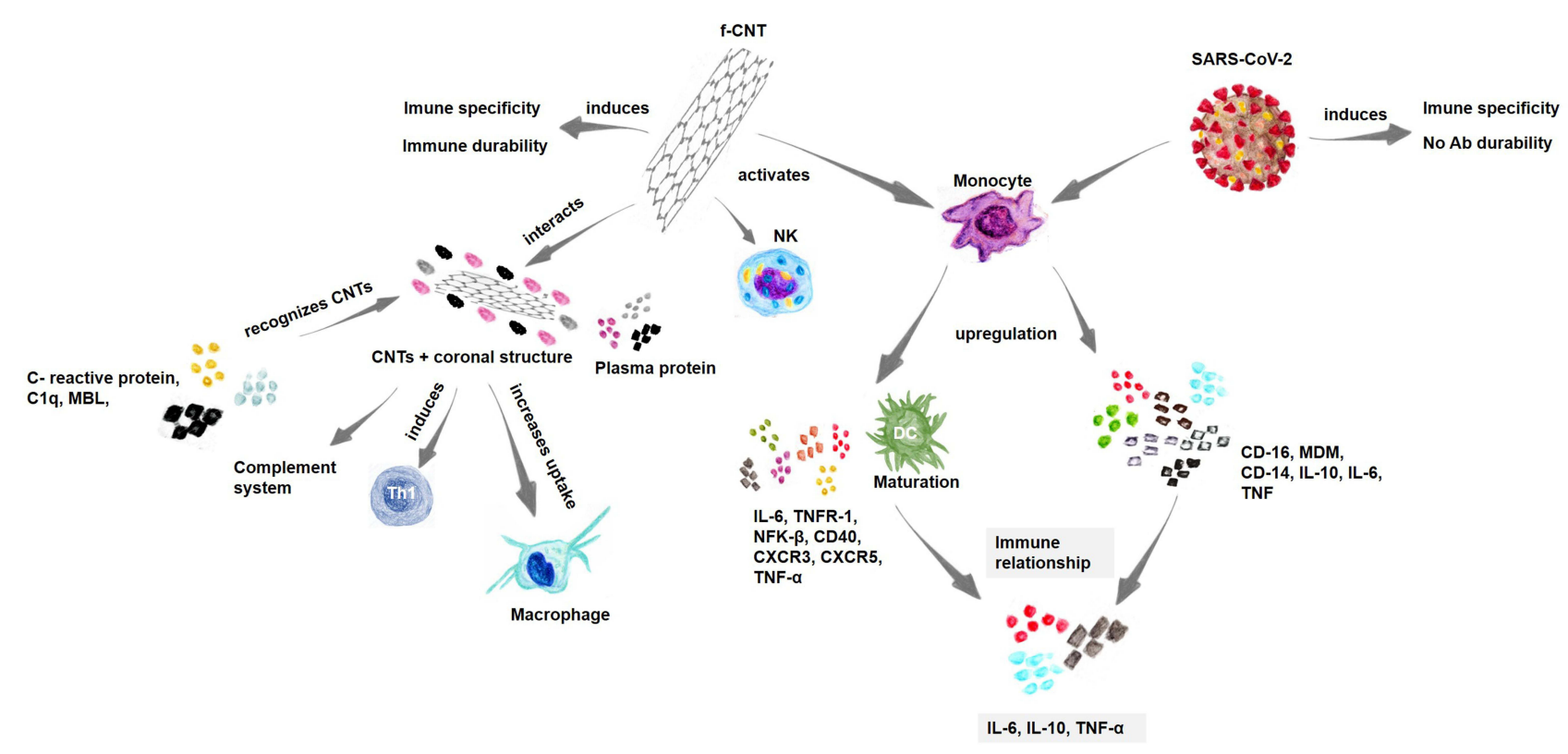

Figure 2 Immune relationship between coronavirus and CNTs.

Notes: Immunological relationship between the immune response induced by coronavirus infection, and the immune response induced by $\mathrm{CNTs}$. Data from references 84 , 89 , and 91 . 
Opsonins that make up the coronal structure, which also includes IgG and complement proteins, increase the uptake of these nanoparticles by macrophages and other cells in the reticuloendothelial system. Complement C1q, MBL, and C-reactive protein recognize repetitive structures or charge patterns on the surface of f-CNTs, and NK cells are stimulated by CNTs (Figure 3A). ${ }^{81}$

When internalizing CNTs, monocytes induce caspase-1-related IL1 $\beta$ secretion and activation of the NLRP3 inflammasome, and after oxidation and functionalization with ammonium groups through 1.3-dipolar cycloaddition, f-CNTs induce CD25 activation and the markers CD14+, IL1 $\beta$, IL-6, TNF, and IL-10. ${ }^{93}$ f-CNTs induce profound modulation of inflammatory molecules at the transcriptome level, and the molecular pathways activated by these nanotubes include TLR, IL-6, DC maturation, TNF, NF-kB, and T-h 1-chemokine pathways (CXCR3 and CCR5 ligand pathways) (Figure 3A). ${ }^{66}$ Therefore, T-cell anti-CD3 complex antibodies immobilized on SWCNTs exhibit effective cellular activity with the presentation of high-density protein stimuli. ${ }^{94,95}$

Results have demonstrated the potential benefits of CNTs as delivery systems for vaccines against different diseases, including cancer. ${ }^{96}$ CNTs is a transport system for small or large therapeutic molecules. The differential of the use of CNTs is that they can be functionalized with functional groups of interest to manipulate their physical or biological properties. Thus, the possibility of manipulating their surfaces and physical dimensions are studied for use in the photothermal destruction of cancer cells. ${ }^{97}$ Also, results obtained by Ouyang et al, showed the immunotherapeutic robustness of $\mathrm{CpG}$, carbon nanotube and temozolomide association. This association improved survival rate in invasive mouse glioma model. The improved antitumor efficacy was related to increased tumor-specific cytotoxic activity in splenocyte cells. ${ }^{98}$

A

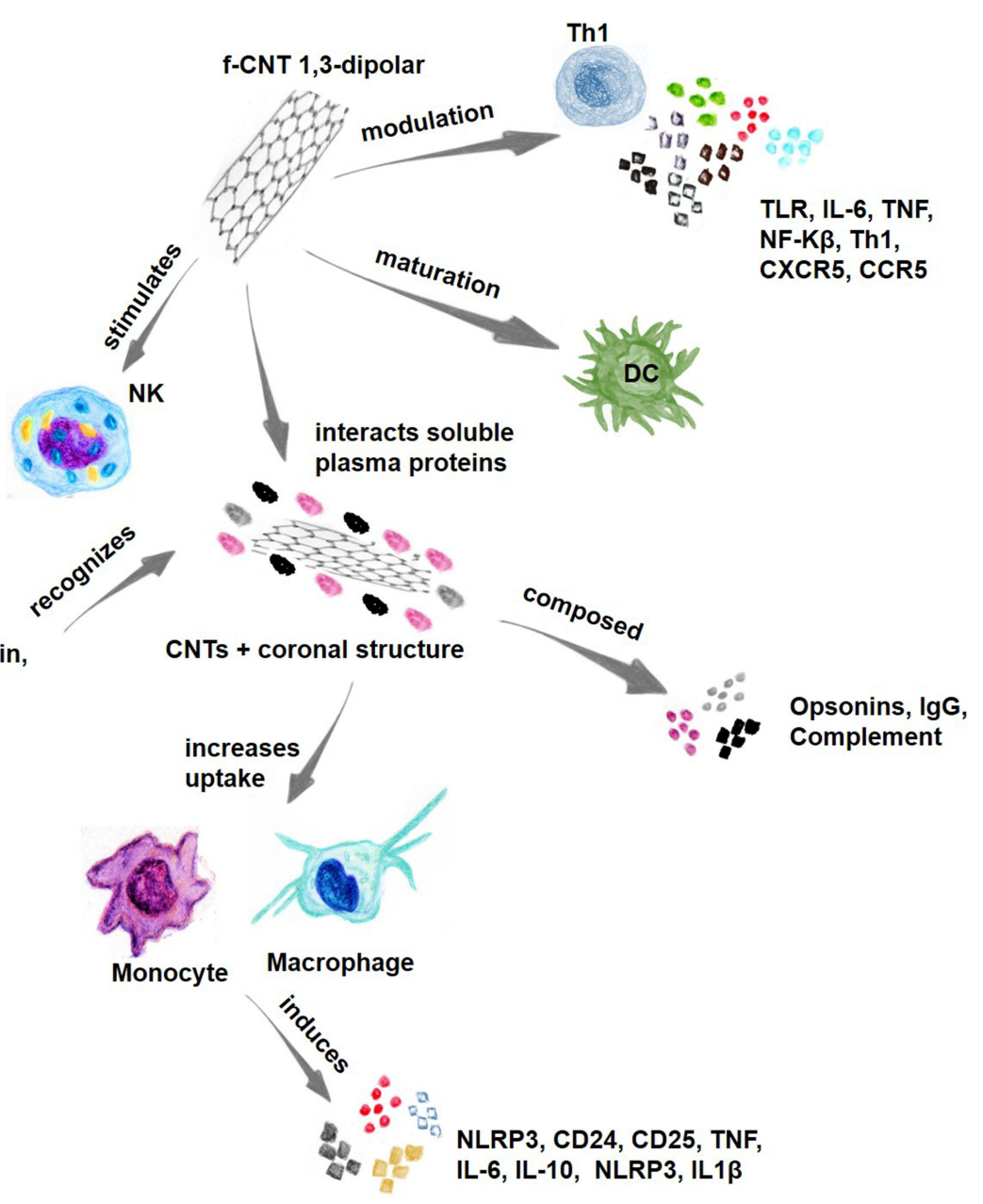

Figure 3 Continue. 


\section{CNTs as RNAi Agents}

RNAi is an efficient tool in medicine for the treatment of different disorders, and has great prospects for use in various fields of action. The RNAi mechanism is triggered by small interfering RNA (about 21-23 nucleotides long), inducing the selective degradation and destruction of complementary mRNA. ${ }^{99}$ In addition, studies have shown that, when complexed-functionalized, the association of siRNA-SWCNT, protects siRNA from enzymatic degradation. ${ }^{100}$

B f-CNT SIRNA
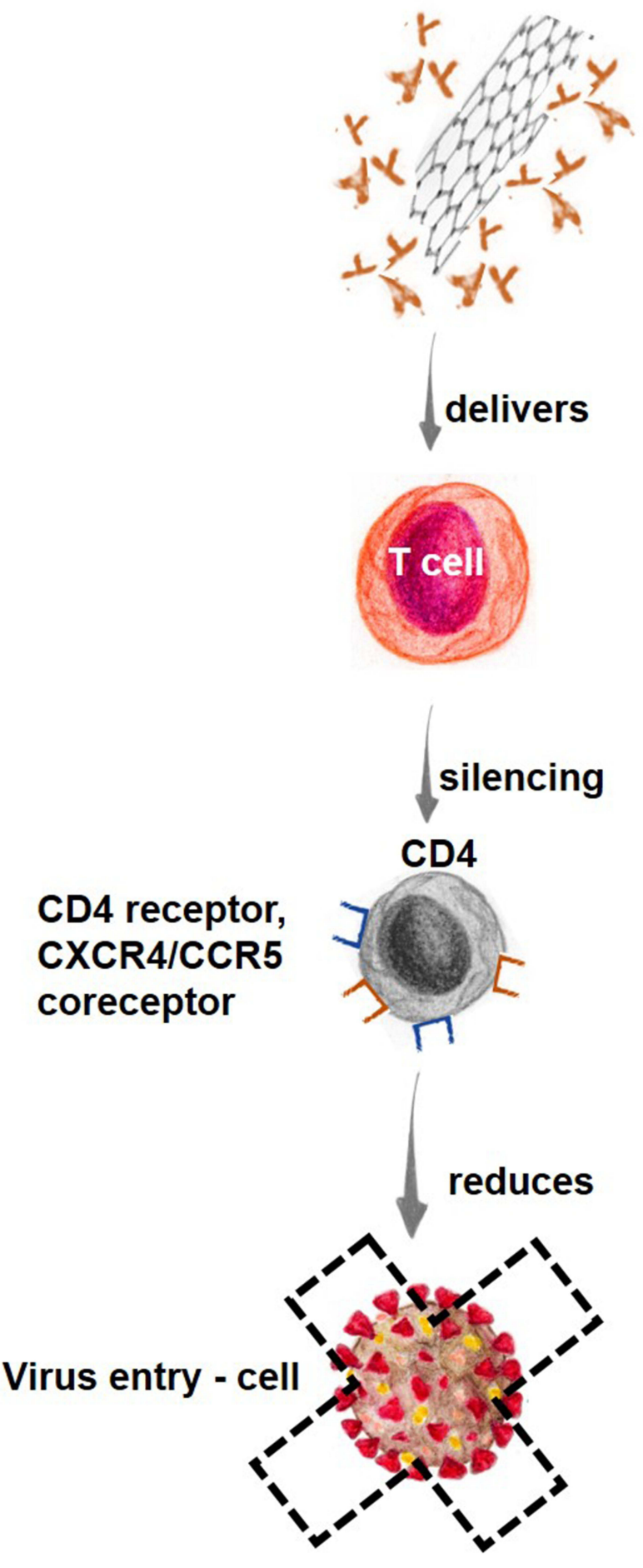

Figure 3 Continue. 


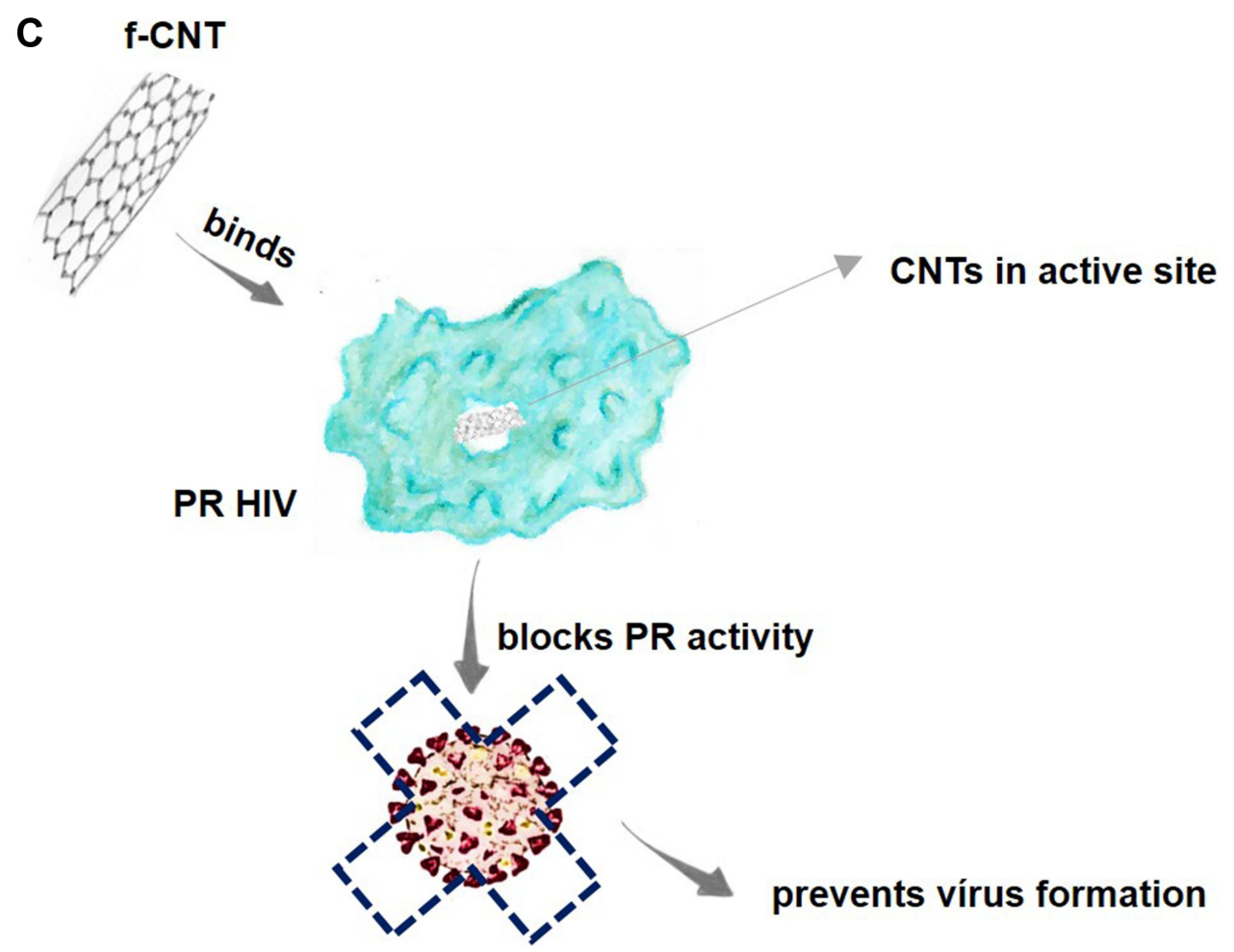

Figure 3 Continue.

Because of their capacity to cross cell membranes via endocytic mechanisms, CNTs have been used to transport several biological molecules, including DNA, proteins, and siRNA. ${ }^{101}$ Specifically, the use of siRNAs has become a method in biological research and potential treatment of human diseases, including AIDS and cancer. ${ }^{102}$ Previous studies have shown the efficiency of CNTs in delivering siRNA into human T cells to silence the expression of HIV receptor-specific cell surface CD4 in addition to CXCR4/CCR5 coreceptors, blocking HIV entry and reducing infectivity (Figure 3B). ${ }^{99}$

Researchers have also explored the use of CNTs as nonviral molecular transporters for siRNA delivery into human T cells, demonstrating that CNTs can deliver siRNA against CXCR4 and CD4 receptors into human T cells and PBMCs. Therefore, compared with transfection agents, including liposome formulations, CNTs show high siRNA delivery efficiency.$^{99}$ CNTs are used to suppress tumor growth through the delivery of siRNA. In this case, CNTs are functionalized to carry siRNA in the CNT sidewalls into tumor cells to silence the target gene; specifically, CNTs have been shown to enter cultured murine tumor cell lines rapidly and inhibit target gene expression, leading to tumor growth arrest. ${ }^{103}$

\section{CNTs in Viral Treatments}

Infectious diseases represent a serious public health problem, with sometimes-catastrophic global impacts, as is the case with coronavirus. Nanotechnology has the advantage of being able to be applied in rapid diagnostic tests, as well as the possibility of using nanoparticles as antiviral agents in effective therapies to combat various infectious diseases, which can be treated through drug delivery systems (DDSs) or interactions of bioactive molecules that induce an efficient immune system response. ${ }^{104}$ The use of nanotechnology is primarily based on molecular principles suggesting that the nanocomposition is associated with physicochemical characteristics that can greatly affect its interaction with the cells of the immune system. Immune cells can take up nanocarriers, which can regulate cellular responses, facilitating access to specific immune cell populations. ${ }^{105,106}$

CNTs can potentially be used to treat several pathogenic viruses, including HIV-1, dengue virus, influenza virus, and coronaviruses. Previous studies have demonstrated that CNTs can bind to the active site of an HIV-1 protease, 
blocking its function. The active site of HIV-1PR can be described as an open cylindrical tube that is lined almost exclusively with hydrophobic amino acids, with cleaving polypeptides involved in the production of the mature virus. Once the polypeptides enter the active site through open flaps, the flaps close and allow the protease to function. ${ }^{46,107,108}$ Nanoparticles are stable and do not readily react with other chemical compounds, but CNTs show high affinity for HIV-PR due to their geometric complementarity and strong van der Waals force interactions with the protease active site. Therefore, the use of CNTs can effectively prevent flap opening after binding to the HIV-1PR active site (Figure 3C). ${ }^{109}$

CNTs also act on HIV-1 integrase protein (IN), which plays an important role in integrating viral DNA into the human genome. To demonstrate the ability of CNTs to inhibit IN, a molecular dynamics (MD) simulation was performed to study the binding of a CNT to full-length HIV-1 IN. The results showed that CNTs can bind stably to the C-terminal domain (CTD) of HIV-1 IN. Additionally, CNTs induce a domain shift, disrupting the binding channel in viral DNA and inhibiting the activity of HIV-1 IN (Figure 3D). ${ }^{86}$

The regulation of the immune response against HIV, to which cytotoxic CD8+ T cell responses appear to be relatively normal, is affected by delayed or abrogated neutralizing antibody production by B cells. ${ }^{110}$ Immunotherapy for HIV/aids can be based on the delivery of antigens or cytokines such as IL-2, IL-7, and IL-15. ${ }^{111}$ Cellular and humoral immunity development requires APCs to process and present antigens to CD4+ and CD8+ T cells. ${ }^{12,113}$ To this end, DCs are professional APCs critical for initiating and coordinating the development of cellular and humoral (antibody) immunity.

Protein/peptide antigens or DNA immunogens (which can lead to endogenous protein expression) can be delivered to endogenous DCs or generated ex vivo, providing a clear perspective on how nanotechnology can be used in immunotherapy. ${ }^{70}$ Interestingly, f-SWCNTs coated with arginine residues to mimic the HIV-1 immunodominant viral peptide KK10 (CNT peptide) can mimic binding to a human leukocyte antigen T-cell receptor (HLA-TCR) immune complex, which reveals the potential for the development of vaccines against HIV. ${ }^{114,115}$ The introduction of a peptide

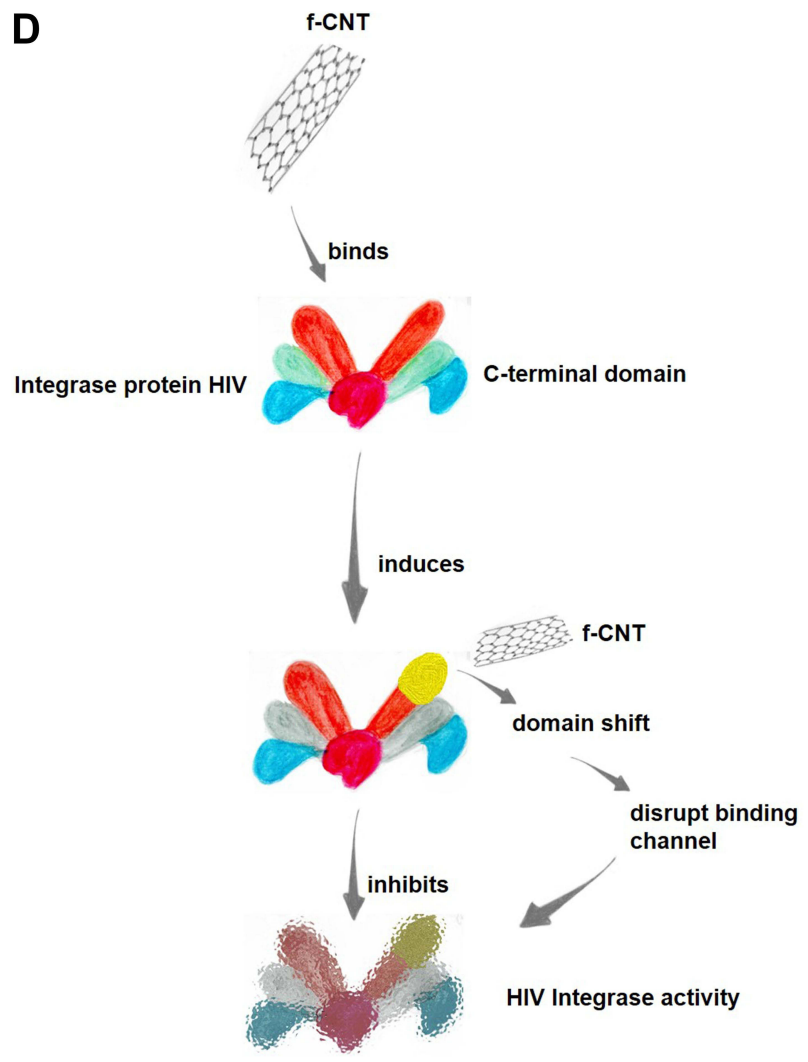

Figure 3 Continue. 
E

\section{f-CNT}
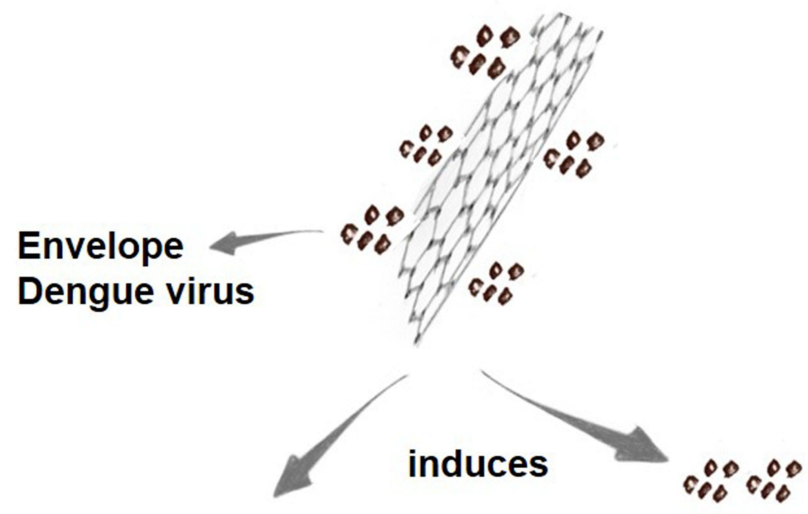

Robust immune response

$\therefore \%$ Specific antibody

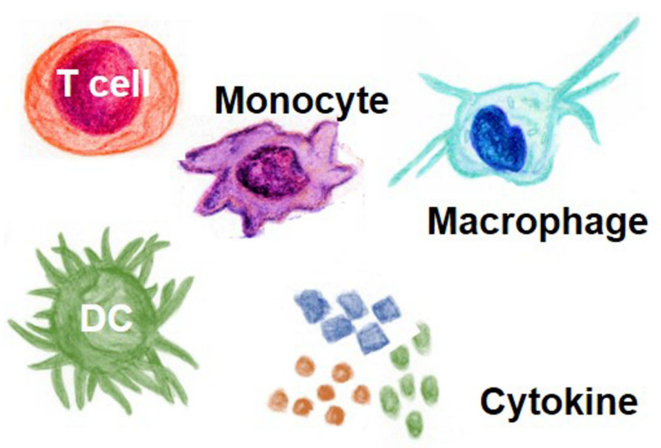

Figure 3 CNTs use in immunotherapy.

Notes: (A-E) Advances in research using CNTs as immunotherapeutic agents through RNAi and in treatments/vaccines of different viral infections. Data from references 89,93 , and $96-102$.

into the body can train and enhance their recognition by the T cells they are activating, controlling HIV-1 infection. In this case, CNT peptides would not be easily degraded in vivo upon binding to the TCR. The proposed CNT peptide represents an alternative to training CTLs for therapeutic purposes in the fight against HIV-1 infection. ${ }^{116}$

Studies have demonstrated that CNTs covalently functionalized with dengue virus serotype 3-recombinant envelope nanoconjugates (MWCNT-DENV3E) induce significant and specific immune responses in mice, demonstrating that CNTs can enhance the immune response against these antigens. Interestingly, the experimental antigen tested generated immunological responses specific only to dengue virus serotype 3 but with prospects for proteins derived from other dengue serotypes. ${ }^{117}$ The effectiveness of CNTs in increasing the expression of a dengue virus tetravalent plasmid vaccine candidate (TVC) has also been studied in vitro with Vero cells and in vivo through intramuscular injection. The results demonstrated that CNTs associated with plasmids are internalized by Vero cells and subsequently disperse into the cytoplasm and nucleus (Figure 3E). ${ }^{118}$

Previous studies have shown that CNTs show great potential to modulate the Th2-type immune response, and an increase in antibody-producing B cells has been observed in mice immunized with CNTs. ${ }^{105}$ However, the researchers pointed out that further studies need to be carried out to improve the immune response, such as by improving the Th1 pattern and achieving the same response with all serotypes, since the study showed different responses, suggesting a relationship with the position of each constructed epitope since secondary structure is one of the determinants of antigenicity and specificity. ${ }^{117,118}$

CNTs have also been used in viral treatments. The methodology involves preparing these nanomaterials in water, covalently attaching them to a B-cell epitope to make them soluble and subsequently neutralizing them with FMDV. ${ }^{92}$ 
The immunological features reported by this study indicated that after conjugation with CNTs for antibody recognition, the epitope was efficiently presented and the CNT peptide triggered strong anti-peptide antibody responses. In this study, CNTs linked to synthetic peptides were used to combat FMD virus, and this CNT-based strategy was effective in improving the immunogenicity of the targeting complexes. As a model antigen, a B-cell epitope of FMDV was selected because it corresponds to the 141-159 amino acid sequence of the viral VP1 protein, and the N-terminus was modified with an acetylated cysteine residue. The peptide was bound to f-CNTs, which were recognized by antibodies at a level equal to antibody recognition of the free peptide. ${ }^{114}$

Compared to the free peptide, the FMDV peptide was free or conjugated to CNTs and the CNT-coupled peptide showed improved antibody responses against FMDV, with a greater ability to neutralize the virus. The results obtained demonstrated that the peptide bound to the CNT support adopted the secondary conformation required for recognition by specific antibodies, which highlighted the potential use of CNT conjugates for the multivalent presentation of molecules to modulate ligand-receptor interactions. ${ }^{119}$

Another interesting and efficient use of CNTs in fighting viral infections involves the treatment of fish disease/infections. CNTs are used to fight infectious spleen and kidney necrosis virus (ISKNV), which infects mandarin fish (Siniperca chuatsi). ${ }^{120}$ In ISKNV infection, the major capsid protein gene (MCP) is the structural protein, and it was selected to make a DNA vaccine based on CNTs with a recombinant plasmid (pcDNA-MCP). The immune response induced by the DNA vaccine to combat ISKNV in mandarin fish was stronger and lasted longer than that induced in fish vaccinated with MCP alone, especially in terms of serum antibody production, enzymatic activity, and immune system gene expression. ${ }^{120,121}$

Studies have shown the efficacy of using CNTs against largemouth bass ulcerative syndrome virus (LBUSV), which induces mortality, in these fish (Micropterus salmoides). SWCNTs containing the capsid protein subunit (MCP) of LBUSV entered fish cells and expressed the MCP protein, and as the protein released by the SWCNTs increased, more antigenic protein was expressed, which induced a robust immune response. Thus, increased serum antibody levels, enzymatic activity, and expression of immune system-related genes (IgM, TGF- $\beta$, IL-1 $\beta$, IL-8, TNF- $\alpha$, and CD4) were evident in the groups immunized with SWCNTs-MCP compared to the group immunized with MCP alone. ${ }^{122}$

Recombinant DNA plasmids combined with CNTs have revealed that immunized fish, show a significant increase in IgM gene expression in relation to the immune system. ${ }^{123}$ In one study, Koi herpesvirus (KHV), also called cyprinid herpesvirus 3 (CyHV-3), which affects common carp and ornamental koi carp production, was assessed. ${ }^{123,124}$ The KHV ORF149 gene encodes a major immunogenic protein in KHV. In this study, a plasmid expression vector for ORF149 coupled to SWCNTs was used as an anti-KHV vaccine. This recombinant molecule was used to immunize fish via intramuscular injection, and subsequently, it was observed that the functionalized SWCNTs loaded with the KHV ORF149 gene conferred long-term and significant protection against KHV. ${ }^{123}$

A previous study analyzed the use of CNTs against grass carp reovirus (GCRV), which causes hemorrhagic disease and is considered one of the most severe threats to this fish species, causing substantial economic losses in the grass carp farming industry. ${ }^{125}$ In this study, the VP43 GCRV subunit vaccine (SWCNT-MVP43) was manually loaded with modified f-CNTs. The results showed that after administration of the functionalized SWCNTs, the immunological parameters increased significantly, and infections caused by GCRV were controlled. ${ }^{126}$ Similarly, studies have shown that DNA-vaccine-loaded CNTs stimulate long-lasting innate and adaptive immunity, protecting against GCRV. In these studies, CNTs were used to deliver GCRV subunit proteins such as VP4, VP5, VP7 and glycoprotein G, and the immunoprotective effects obtained reveal the potential of using CNTs against viral pathogens. ${ }^{127,128}$

\section{The Potential Use of Carbon Nanotubes and Metallic Nanoparticles in Immunotherapy}

CNTs are excellent candidates for theranostic use due to their physical-chemical properties and morphology that allow their functionalization. ${ }^{129}$ Several research groups are investigating the use of carbon nanotubes as an antitumor agent. Different methods have been developed - used to couple therapeutic and fluorescent molecules onto carbon nanotubes to achieve an antitumor action. ${ }^{130}$ Studies have shown that the immune response is enhanced when immunotherapy is based on nanoparticulate agents, with special attention to the immunomodulatory action of CNTs. ${ }^{131}$ 
A common feature of CNTs is the thermal effect of these nanomaterials. Phototherapy in cancer treatment using CNTs has shown good results, since these nanomaterials can absorb near-infrared (NIR) light, which results in the heating of the nanotubes and consequently in the destruction of the tumor cell. ${ }^{132}$ Results showed that CNTs are excellent candidates for immunomodulation, enhancing antitumor immune activity in murine models. ${ }^{133}$ Oxidized and subcutaneously administered CNTs promote activation of the complement system, activation of inflammatory cytokines and macrophages, resulting in inhibition of tumor growth. ${ }^{134}$ In this regard, there is growing interest in the use of CNTs for immunotherapeutic applications. ${ }^{94}$

The possibility of adapting CNTs for immunotherapeutic applications that involve presentation of artificial antigens, genetic delivery of immune vectors, delivery of therapeutic drug-molecules, requires understanding the methods that mitigate the interactions between CNTs and key components of the immune system. Thus, possible toxic effects can be minimized according to the methods involved in CNTs functionalization, chemical-physical treatment, as well as the incubation time of this nanomaterial. ${ }^{135}$

Other good candidates for application in nanomedicine are metallic nanoparticles and semiconductors, which are mostly developed as components of electronic nanodevices. Metallic nanoparticles, especially the noble metals such as gold, silver and copper, possess unique optical and electrical properties, called localized surface plasmon resonance (LSPR). ${ }^{136}$ Gold nanoparticles are some of the most common classes of nanomaterials used in studies for viral diagnosis and/or treatment due to their optical properties, biocompatibility and stability of this nanoparticle. ${ }^{137}$ There is a good interaction between CNTs and these nanomaterials, for example, the robust interaction between gold nanoparticles and CNTs, confirming a stable bond between these nanomaterials, however in this section of the manuscript, each metal nanoparticle will be treated separately. ${ }^{138}$

Gold nanoparticles have been used in rapid diagnostic tests for the detection of COVID-19. Detection of the viral particle occurs by the sensitivity of detection of the colorimetric assays. ${ }^{139}$ Results show that the anti-protein-spike antibody, associated with gold nanoparticles, can detect and prevent the growth of viral particles, interfering with replication. Gold nanoparticles present biocompatibility, optical properties and the possibility of surface modification by functionalization methods, demonstrating that they are good agents as theranostic nanoplatforms. ${ }^{140}$ The sensitivity of gold nanoparticles can be used to detect very low levels of different viruses, cancer cells, bacteria and other biomolecules of clinical interest. As a sensor, gold nanoparticles can detect the COVID-19 antigen at a concentration of 1 nanogram per $\mathrm{mL}$ in a concentration of 1000 virus particles per $\mathrm{mL} .{ }^{140}$

Gold nanoparticles associated with antibodies for coronavirus detection have a rapid viral detection capability, getting results as fast as a few minutes. SARS-CoV-2 infection starts with the binding of receptors on the cells mediated by the spike protein tip. Different research groups have been developing inhibitors of viral-cell receptor-binding mechanisms to prevent the entry of the virus into the host cells. ${ }^{141,142}$ It has been shown that gold nanoparticles can block the spread of SARS-CoV-2 virus in HEK293T cells expressing the ACE2 receptor. ${ }^{140}$ Additionally, gold nanoparticles, functionalized against different viruses, show strong antiviral action, especially against herpes simplex virus (HSV) and respiratory syncytial virus (RSV). ${ }^{143}$ Atomistic simulation (MD) studies show a more stable binding complex that indicates that this nanostructure has great potential to bind to the RBD of SARS-CoV-2 and could be proposed as an inhibitor against COVID-19. ${ }^{141}$

Gold nanoparticles can be functionalized, by modifying their surface for diagnostic use. Studies have shown that colloidal nanoparticles conjugated with streptavidin can detect MERS-CoV. ${ }^{144}$ This rapid detection capability, after 35 minutes, allows to visualize the result with the naked eye. Interestingly, the viral detection is around $10 \mathrm{copies} / \mu \mathrm{L}$ of MERS-CoV RNA. The gold nanoparticles were functionalized with thiol-modified cDNA receptors of viral gene sequences (RdRpCOVID or RdRp-SARS) to create the LSPR sensor, which can improve viral detection performance, with a specificity-sensitivity range of $0.22 \mathrm{pM} .{ }^{145}$

Silver nanoparticles (AgNPs) are also another type of nanoparticle of immunotherapeutic and diagnostic interest due to their antimicrobial, antiviral and immunomodulatory properties. ${ }^{146,147}$ Studies have demonstrated the efficacy of AgNPs as potent antiviral agents and it is presumed that they can be effective against coronaviruses species. AgNPs can generate free radicals and reactive oxygen species (ROS), inducing cell death and consequently preventing viral 
infection. ${ }^{148}$ Importantly, both the size and shape of AgNPs play a key role in biomedical applications, as these morphological changes modify the outcome of these interactions and biological activities. ${ }^{149}$

Commercialized AgNPs are considered potentially therapeutic and can induce an immune response, causing inflammatory cell apoptosis in the host. AgNPs have a great capacity to attenuate the progression of multiple diseases, and among the products already on the market, we can mention PolyMem Silver ${ }^{\mathrm{TM}}$ (Aspen), Acticoat ${ }^{\mathrm{TM}}$ e Bactigras ${ }^{\mathrm{TM}}$ (Smith \& Nephew), Tegaderm ${ }^{\mathrm{TM}}$ (3 M) e Aquacel ${ }^{\mathrm{TM}}$ (ConvaTec). ${ }^{150}$

AgNPs represent promising therapeutic agents in the fight against coronaviruses, due to their anti-inflammatory and pulmonary antifibrotic properties, especially because of the immunomodulatory capacity and transcriptional activity induced by this nanomaterial. Results show that after the use of AgNPs, there is a reduction in the concentrations of inflammatory cytokines such as IL-1 $\beta$, IL-6, IL-17, and tumor necrosis factor alpha (TNF- $\alpha) .{ }^{151}$ An important factor of AgNPs is the possibility of use in diagnostics and imaging, due to the electronic, catalytic, and photonic characteristics, and due to surface functionalization possibilities, which occurs by covalent bonding or affinity interactions. ${ }^{152}$

The properties of this nanomaterial enable its use in theranostics, through functional platforms, with antibacterial, anticancer, drug delivery system and/or diagnostic-bioimaging action. ${ }^{153}$ In addition, AgNPs are versatile and highly sensitive for the detection of biomolecules in the detection of pathogens and/or viral particles, which is of utmost importance in the battle against coronaviruses and future pandemic pathogens. ${ }^{154,155}$ The knowledge of the action of these nanoparticles is fundamental for further use in future epidemics or pandemics. AgNPs may prove useful in future pandemics, due to the possibility of manipulating and functionalizing this nanomaterial, as well as being able to target the biocompatibility and specificity. ${ }^{156}$ There are many perspectives for the use of these nanomaterials as immunotherapeutic agents, especially through the development of vaccines and therapeutic and/or prophylactic drug-molecules, associated with sanitary-sanitizing products, as well as safety equipment with these nanotechnologies, to mitigate viral propagation. ${ }^{157}$

Another nanoparticle that is being investigated to combat coronaviruses is cerium oxide or nanoceria for use as a carrier molecule to treat acute lung injury. ${ }^{158}$ These nanoparticles possess remarkable regenerative, anti-inflammatory, antioxidant, and antifibrotic properties, which makes this nanoparticle a promising agent in combating coronavirus and/or its associated systemic complications. ${ }^{159}$

A critical complication of coronavirus infection, is chronic acute respiratory syndrome, which is orchestrated by an interplay of signaling and activation of inflammatory molecules and pathways such as i) activation of nuclear factor kappa-beta B-cell activation (NFkB), ii) cytokine storm, and iii) mitogen-activated protein kinases (MAPKs). ${ }^{160}$ In this sense, nanoceria possess antioxidant properties and characteristics mimicking catalase and superoxide dismutase activity and represent a promising agent for anti-inflammatory use through the inhibition of both NFkB and MAPK pathways. ${ }^{161}$ Interestingly, this same anti-inflammatory activity of nanoceria can be found with the use of bilirubin, a metabolic hormone. ${ }^{159}$ For example, bilirubin delivery nanoparticles induce anti-inflammatory and immunomodulatory activities by modulating the expression of the NFKB and MAPKinase pathways, which may represent a new immunotherapeutic strategy against COVID-19. ${ }^{162}$

Nanoceria exhibit anti-inflammatory properties, which have the potential to inhibit the chronic inflammatory response and reduce lung fibrosis during coronavirus infection by decreasing cytokine activation, especially in the modulation of MAP kinase/NFkB-like pathways. Nanoceria can decrease the effects of cytokine storm progression, reducing the incidence of acute respiratory distress syndrome (ARDS). Excess oxidative stress is common in cases of acute lung injury, where leukocytes play a key role in free radical synthesis, and increased ROS are involved in the release of proinflammatory cytokines. ${ }^{163}$

Nanoceria have an action in reducing leukocyte recruitment and in reducing ROS activation. ${ }^{159}$ Studies show that when nanoceria are associated with miR146a, improvement in lung capacity occurs, including improved lung mechanics, increased tissue resistance and inspiratory capacity, and improved lung elastance. ${ }^{164}$

Furthermore, in the fight against coronaviruses, copper nanoparticles, or copper oxide, may be an excellent option among the application possibilities of nanotechnology. ${ }^{165}$ Copper is naturally present in many species of plants and animals. ${ }^{166}$ Copper nanoparticles, or copper oxide nanoparticles, have important applications as biocides, as well as antiviral action against different viruses. ${ }^{167}$ Copper, similar to silver, has been universally recognized as a potent 
antimicrobial for a few millennia and is known to be applied for different applications in antiquity against infections in both animals and humans. ${ }^{168}$ Copper nanoparticles have antiviral actions that are related to the inhibition of the mechanisms of entry, attachment or viral replication. AgNPs interact with glycoproteins, as in a viral competition system, related to the entry into the host cell blocking cell receptors. ${ }^{169}$

Additionally, copper nanoparticles inactivate viral particles and virion progenitors by interacting with the viral genome, which ultimately prevents entry into the cell. Studies have shown the efficiency of copper nanoparticles in their antiviral activity against the influenza A (H1N1) virus. This antiviral activity occurs by the degradation of viral proteins due to the generation of hydroxyl radicals and copper ions. ${ }^{167}$

Due to its antiviral and antimicrobial properties, copper is a potent antiviral agent that may be useful in this SARS$\mathrm{CoV}-2$ pandemic and prospectively be useful in future pandemics. ${ }^{146}$ Copper is a good candidate in the fight against viral infections and can be useful in public spaces and common touch sites/surfaces, which can decrease the transmission rate in common places with much public access. One of the antimicrobial characteristics of copper is that it is a potent inducer of ROS. For example, increased ROS disrupts the coccolithovirus life cycle. In addition, copper-treated surfaces minimize the amount of microorganisms in the environment. ${ }^{170}$

\section{Challenges in Using Carbon Nanotubes as Immunotherapeutic Agents Toxicity, Functionalization, and Biodegradation}

Due to the unique properties of nanomaterials, their interactions can have significant biological effects, and they can remain in the environment, outside and inside humans, for a long time, causing toxic effects and various other undesirable reactions. ${ }^{171}$ For example, CNTs are often compared to asbestos fibers, which cause pulmonary toxicity, oxidative stress processes, and general damage to the immune system (Figure 4). ${ }^{93}$ However, when CNTs are functionalized (f-CNTs) via the use of different methods (PEGylation, and amino acids, among other compounds), the inflammation levels they induce are reduced. ${ }^{172}$

Nonfunctionalized CNT-PCNTs can induce oxidative stress in cells, leading to the production of proteins such as kinases and nuclear factor-kappa $\mathrm{B} ;{ }^{173}$ these proteins are critical for the signaling regulation of cytokines in response to oxidative stress. Another issue is that CNTs are not easily eliminated from the body, with risks of accumulation in different organs, including the lungs, kidneys, and spleen. These organs are usually targets of free radicals that induce oxidative stress. Furthermore, nonfunctionalized CNTs tend to bind to various cytoplasmic proteins, thereby activating the innate immune response and the complement system and triggering inflammatory processes (Figure 4). ${ }^{174}$

Based on these observations, the main concern associated with the use of CNTs as immunotherapy is the risk of bioaccumulation and/or toxicity. ${ }^{175}$ However, the functionalization of CNTs is expected to render them biocompatible and water soluble, thereby reducing their toxicity and preventing their accumulation in biological structures. ${ }^{80}$ Another challenge in using CNTs involves their nonoptimal biodegradation/elimination. ${ }^{176}$ The biodegradation of CNTs was first described by Allen et al in 2008; they showed that enzymatic oxidation by horseradish peroxidase (HRP) a plant enzyme, oxidized these nanomaterials. ${ }^{177}$ In addition, CNTs were shown to be degraded in myeloperoxidase (MPO), an animal enzyme that is expressed in neutrophils, and in eosinophil peroxidase (EPO). Various studies have shown the biodegradation of CNTs using enzymes such as lignin peroxidases, xanthine oxidases, and manganese peroxidases, which have proven the capacity for CNT degradation. ${ }^{178,179}$

Previous studies have shown that macrophages pretreated with MPO inhibitors and ROS inhibitors showed increased degradation rates. ${ }^{180}$ The MPO enzyme can facilitate the interaction of $\mathrm{H} 2 \mathrm{O} 2$ with $\mathrm{Cl}$ to produce hypochlorites that attack CNT walls and carbon bonds, creating holes in CNT structures, causing their degradation. ${ }^{181}$ The final process in this enzymatic pathway results in an oxidative burst that culminates in CNT degradation. ${ }^{182}$ After biodegradation, CNTs are eliminated through cell stress-activated exocytic mechanisms via endosomes of the trans-Golgi complex. The degradation of CNTs is affected by several factors, particularly those related to the size and composition of the nanotube wall, as well as the type of surface treatment on this nanomaterial. ${ }^{66,183}$ 


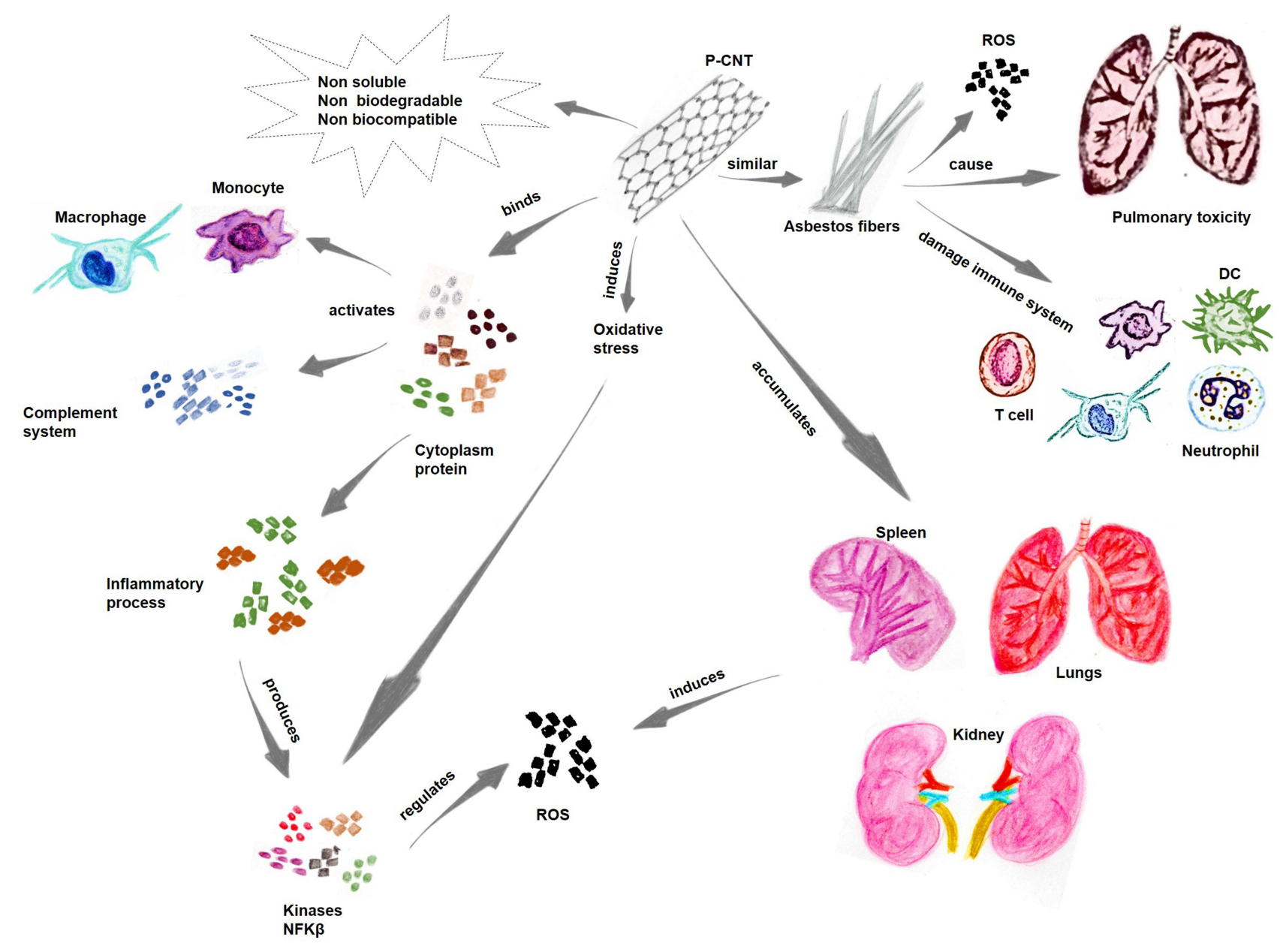

Figure 4 Challenges in using CNTs as immunotherapeutic agents.

Notes: The challenges of using nanotubes as immunotherapeutic agents include cytotoxicity, biodistribution and elimination of the nanomaterials from biological systems. Data from references $173-176$.

\section{How Can Carbon Nanotubes/Nanoplatforms Help in Other Pathologies and Future Pandemics?}

Similar to CNTs, other nanoparticles have been used in biological processes. ${ }^{46}$ Additionally, associated with these approaches, molecular methods such as mRNA vaccines are being developed for the treatment of COVID-19. ${ }^{184}$ The use of nanoparticles can improve the stability and protect the mRNA from enzymatic processes and direct the delivery of the molecular material sent to the target site. Nanoparticles in carrier-nanoplatform systems have unique advantages compared to other carrier systems, including a larger surface area, specific drug targeting, pharmacokinetics, among others. ${ }^{185,186}$

Nanotechnology quickly made possible the development of an mRNA vaccine, which was developed by Moderna and Pfizer/BioNTech. ${ }^{187}$ The efficacy of these mRNA vaccines, based on the spike protein, reaches more than $94 \%$ efficacy against SARS-CoV-2. Nanocarrier-based vaccines show better performance due to important factors that i) facilitate the molecular delivery system, ii) protect the molecule against degrading enzymes and iii) improve biodistribution. ${ }^{188}$

The development and application of various nanomaterials-nanoparticles has acted directly in numerous improvements, especially in the association-acquisition of knowledge that is subsequently applied in different diseases. Thus, in current or future pandemics, prior knowledge, even if partial, about the pathogen, improves the chances of success in the control/combat of various diseases. ${ }^{184}$ All this knowledge acquired-applied to nanotechnology, especially with the use of 
the carrier effect method, has brought insight and improved techniques that bring great possibilities of treatment for different diseases, besides new knowledge that can be applied in future pandemics. ${ }^{13,189}$

\section{Discussion \& Prospects Concerning the Use of Carbon-Based Nanomaterials in Immunotherapy}

The current SARS-CoV-2 pandemic has boosted the knowledge applications of nanotechnology, through the development of new materials such as surgical masks, gloves, textiles and especially immunological therapy, which covers therapeutic molecules, vaccines and diagnostics. ${ }^{167}$ Among the possibilities of using nanoparticles in theranostics, especially in immunotherapies and vaccines, carbon-based nanomaterials such as carbon dots (CD) also called quantum dots (CQDs) and CNTs represent great possibilities through their association with immunotherapeutic molecules for use in different functionalities. ${ }^{134}$

Immunotherapeutic molecules are essential for inducing an immune response against various pathogens. The use of CNTs is promising for enhancing the immunogenicity of a precise antigen. These immunotherapies have advantages over other traditional approaches, especially because they exhibit better extended-release kinetics and immunogenic selectivity. ${ }^{190}$ An exciting approach for CNT-based nanotechnological immunotherapeutic molecules involves the possibility of combining different active and specific antigens to activate a targeted immune pathway. ${ }^{185}$ CNTs are therefore extensively researched nanomaterials for transporting specific molecules to immune system cells, among other goals, aiming to reduce toxicity and increase biocompatibility upon challenge. ${ }^{101,191}$

CNTs are immunomodulatory agents that can be modified and adapted according to the specific activated immune pathway of interest. Several studies have shown the use of CNTs as immunological agents and have shown their capacity to improve immunomodulatory activity. ${ }^{78,90,123,192}$ Immunotherapy is a developing field that leverages technologies capable of improving the specificity of the treatment/cure of several diseases, and because of the nanometric size, CNTs can be readily taken up by phagocytic cells, thereby inducing specificity and efficiency in the recognition and presentation of a specific antigen. ${ }^{46,185}$ Thus, the use of CNTs as therapeutic agents is a growing field of interest with excellent opportunities for developing new therapies based on immunological molecules that depend on the safe development, nontoxicity, biocompatibility, and biodegradability of these nanomaterials. ${ }^{190,193}$

Several studies have discussed the immune responses of coronavirus during outbreaks, including cytokine and chemokine activation and genome expression. ${ }^{25,39,88}$ However, no available studies have discussed/demonstrated a direct relationship between immune activation by the coronavirus and immune activation by CNTs. ${ }^{194}$ In this study, an interesting finding/point of discussion suggests that the cytokines involved in the different coronavirus outbreaks such as IL-6, IL-8, TNF- $\alpha$ and CXCL10, are directly related to the inflammatory signaling pathway, which is not activated in the immune response induced by f-CNTs. Surprisingly, no differences were found in the immune activation pathways of either coronaviruses or nanotubes however, this lack of differences is likely due to the few investigations on the immunological aspects of CNT use. In summary, these results corroborate the findings of much of the work done by Prato et al, who studied viral immunotherapies, and those of Dan et al, who studied various aspects of immune activation induced by coronaviruses. ${ }^{50,119}$ Therefore, links between coronavirus and nanotube immune activation are likely.

As previously mentioned, another option in theranostic nanotechnology, which has gained prominence, is the use of carbon dots (CDs), which are members of the family of carbon-based nanomaterials. ${ }^{195} \mathrm{CDs}$ have a very high surface-tovolume ratio, are hydrophobic and environmentally inert, and therefore have been studied for their applications in various fields, including chemical sensing, bioimaging, electrocatalysis, among others. ${ }^{196,197}$ Studies have shown the antiviral efficiency of CDs against different viruses, including HCoV, HIV-1, JEV, ZIKV, DENV and PEDV. ${ }^{198}$

The antiviral properties of carbon-based nanomaterials suggest their ability to be used in immunotherapies against different pathogens and possibly be useful in combating new-future pandemics. Although the mechanisms of action of carbon-based nanomaterials are not very detailed, they have antiviral action through interferon-based immunomodulation. CDs conjugated with specific molecules inhibit the entry of the virus into cells by blocking receptors, preventing viral replication. ${ }^{199}$ 
Within the current situation, we understand that another option for the therapeutic treatment of COVID-19 is urgent and necessary. Carbon-based nanomaterials represent excellent options in the treatment of several diseases due to their antimicrobial action, biocompatibility, biodegradability and tissue regenerative capacity. ${ }^{200}$ Additionally, the functionalization of these carbon-based nanomaterials represents a great alternative in the battle against viral infections, including HIV, dengue, and COVID-19. ${ }^{201}$

The properties of these carbon-based nanomaterials as antiviral agents result from their high surface area, which makes them ideal agents for the transport of therapeutic molecules. ${ }^{202}$ The physicochemical mechanisms of these nanomaterials that include a very high surface area, excellent electrical and thermal conductivity, and biocompatibility, is often related to the antimicrobial properties, due to the ability to disrupt the peptidoglycan structure of the bacterial membrane, through electron transfer and/or through the induction of oxidative stress by reactive oxygen species (ROS). ${ }^{198,203}$

CDs possess properties such as ease of synthesis, tunable fluorescence, photochemical stability, biocompatibility, water solubility and low cytotoxicity, which make them a promising agents for different biological-biomedical applications. ${ }^{204}$ The surface of CDs allows easy association with different therapeutic molecules useful in antiviral applications. CDs are excellent candidates for modulating the viral cycle. The virus binds to host cells through multivalent interactions; therefore, treatment with CDs can prevent the virus from entering host cells. CDs present themselves as efficient candidates for modulating infection by altering the viral cycle; through binding interactions with host cells, CDs can prevent the viruses from entering the cells. ${ }^{205}$

Sensors are critical for rapid detection, and in pandemic times, the demand for more selective and affordable devices for viral diagnostic-detection is high. Studies have shown that CDs have as main mechanisms of action, electron transfer, photoinduced charge transfer and energy transfer, which induces the efficiency for the detection of bacteria and viruses. For this reason, studies have explored this method for the detection of viral RNAs. ${ }^{206}$

Other studies address the use of CDs not only as an immunotherapeutic and vaccine agent, but also as a diagnostic agent for use in biosensor bioimaging. These nanomaterials are excellent immunotherapeutic agents due to the possibility of surface functionalization and their low toxicity, being besides agents for therapeutic delivery systems, theranostic agents, which represent a new step in the production of theranostic nanoparticles in the near future. ${ }^{197}$ Thus, with the results obtained so far, it is possible to direct-improve the development of new approaches and strategic designs for immunotherapies, especially in the fight against coronavirus.

\section{Conclusions}

The main objective of this study was to identify any immune activation relationships between coronavirus infections and CNTs. The use of CNTs represents an advanced approach to immunotherapeutic applications based on the development of new nanotechnological products to treat various viral infections. Issues such as safety and efficacy are urgent issues that need to be addressed/investigated and discussed when considering the use of these types of immunotherapies.

One of the most significant findings in this study showed that the relationship between the immune activation induced by coronaviruses and CNTs is related to cytokines such as IL-6, IL-12 and IFN- $\alpha$ in the C1q pathways. Thus, the following conclusions can be drawn from the present study and can be considered new possibilities for using these immune pathways, particularly with CNTs as immunomodulatory agents to combat coronavirus infections.

The findings of this study have significant implications for understanding how CNTs can be used as immunotherapeutic agents to combat coronavirus infections. This work is the first comprehensive investigation of the relationship between coronavirus infections and immune activation by CNTs, and the knowledge gained from this study may be useful in creating/developing new possibilities in immunotherapies.

However, we acknowledge limitations in this study due to the lack of information on the use of nanotubes as immunotherapeutics against coronaviruses, despite the limitations; this study contributes to the understanding of the convergence and relationships between the activation of immune pathways involving coronaviruses and CNTs, offering insight into new immunotherapeutic possibilities. It is relevant to mention that a limitation concerning this study review is the separation of the articles discussed because there is an extensive literature, and many articles required expanded methodologies and experiments, thus, some hypotheses remain open to new discussions as well as future contributions, primarily in an open speculative and exploratory space. 
With the fight against the SARS-CoV-2 pandemic, the nanotechnology community united informs and shared tools and experiments to achieve good results with the COVID-19 survey. Efforts through research and scientific collaborations with all involved, including an industry and clinical hospital have produced good advances; however, it is essential to have partnerships between all involved so that the path taken by the acquired knowledge can serve as a bridge for development - improvement of new diagnostic methods, new drugs and specific molecules for the cure.

In this sense, for the discussion to move forward, it is necessary to develop a better understanding of this immunological relationship, and to this end, we suggest that new studies are/can be developed/performed on the interactions/relationships and convergence of immunological activation between coronaviruses and CNTs. Therefore, it is urgent and necessary to know the mechanisms that can improve and adapt the different physical and chemical properties of CNTs for use in immunotherapies in the fight against various types of viral infections, particularly COVID-19, for which therapeutic strategies are still rare.

\section{Funding}

This work was financially supported by 2012/1142283 grants from the Coordenação de Aperfeiçoamento de Pessoal de Nível Superior and by Ministério da Saúde MS-SCTIE-Decit/CNP no.12/2018. The funders had no role in the study design, data collection or analysis, the decision to publish or the preparation of the manuscript.

\section{Disclosure}

The authors have no declarations or conflicts of interest associated with this work.

\section{References}

1. Rastogi M, Pandey N, Shukla A, Singh SK. SARS coronavirus 2: from genome to infectome. Respir Res. 2020;21(1):318. doi:10.1186/s12931020-01581-z

2. Pourrajab F, Zare-Khormizi MR, Sheikhha MH. Molecular basis for pathogenicity of human coronaviruses. Infect Drug Resist. 2020;13:2385-2405. doi:10.2147/IDR.S255156

3. Chen Y, Liu Q, Guo D. Emerging coronaviruses: genome structure, replication, and pathogenesis. J Med Virol. 2020;92(4):418-423. doi: $10.1002 / \mathrm{jmv} .25681$

4. Cui J, Li F, Shi Z-L. Origin and evolution of pathogenic coronaviruses. Nat Rev Microbiol. 2019;17(3):181-192. doi:10.1038/s41579-018-01189

5. Zhao L, Feng D, Ye R-Z, et al. Outbreak of COVID-19 and SARS in mainland China: a comparative study based on national surveillance data. BMJ Open. 2020;10(10):e043411. doi:10.1136/bmjopen-2020-043411

6. Liu DX, Liang JQ, Fung TS. Human coronavirus-229E, -OC43, -NL63, and -HKU1 (Coronaviridae). Ref Module Life Sci. 2020. doi:10.1016/ B978-0-12-809633-8.21501-X

7. Andersen KG, Rambaut AA, Lipkin WL, Holmes EC, Garry RF. The proximal origin of SARS-CoV-2. Nat Med. 2020. doi:10.1038/s41591020-0820-9

8. Umakanthan S, Sahu P, Ranade AV, et al.Origin, transmission, diagnosis and management of coronavirus disease 2019 (COVID-19). Postgrad Med J. 2020. doi:10.1136/postgradmedj-2020-138234

9. Tay MZ, Poh CM, Rénia L, MacAry PA, Ng LFP. The trinity of COVID-19: immunity, inflammation and intervention. Nat Rev Immunol. 2020;20(6):363-374. doi:10.1038/s41577-020-0311-8

10. Tea F, Ospina Stella A, Aggarwal A, et al. SARS-CoV-2 neutralizing antibodies: longevity, breadth, and evasion by emerging viral variants. PLOS Med. 2021;18(7):e1003656. doi:10.1371/journal.pmed.1003656

11. Nalbant A, Kaya T, Varim C, Yaylaci S, Tamer A, Cinemre H. Can the neutrophil/lymphocyte ratio (NLR) have a role in the diagnosis of coronavirus 2019 disease (COVID-19)? Rev Assoc Med Bras. 2020;66(6):746-751. doi:10.1590/1806-9282.66.6.746

12. de Carvalho Lima EN, Diaz RS, Justo JF, Castilho Piqueira JR. Advances and perspectives in the use of carbon nanotubes in vaccine development. Int J Nanomedicine. 2021;16:5411-5435. doi:10.2147/IJN.S314308

13. Weiss C, Carriere M, Fusco L, et al. Toward nanotechnology-enabled approaches against the COVID-19 pandemic. ACS Nano. 2020;14 (6):6383-6406. doi:10.1021/acsnano.0c03697

14. Huang C, Wang Y, Li X, et al. Clinical features of patients infected with 2019 novel coronavirus in Wuhan, China. Lancet. 2020;395 (10223):497-506. doi:10.1016/S0140-6736(20)30183-5

15. Coleman CM, Liu YV, Mu H, et al. Purified coronavirus spike protein nanoparticles induce coronavirus neutralizing antibodies in mice. Vaccine. 2014;32(26):3169-3174. doi:10.1016/j.vaccine.2014.04.016

16. Zheng B, Peng W, Guo M, et al. Inhalable nanovaccine with biomimetic coronavirus structure to trigger mucosal immunity of respiratory tract against COVID-19. Chem Eng J. 2021;418:129392. doi:10.1016/j.cej.2021.129392

17. Song JW, Zhang C, Fan X, et al.Immunological and inflammatory profiles in mild and severe cases of COVID-19. Nat Commun. 2020;11:1.

18. Yen Y-T, Liao F, Hsiao C-H, Kao C-L, Chen Y-C, Wu-Hsieh BA. Modeling the early events of severe acute respiratory syndrome coronavirus infection in vitro. $J$ Virol. 2006;80(6):2684-2693. doi:10.1128/JVI.80.6.2684-2693.2006

19. Costela-Ruiz VJ, Illescas-Montes R, Puerta-Puerta JM, Ruiz C, Melguizo-Rodríguez L. SARS-CoV-2 infection: the role of cytokines in COVID-19 disease. Cytokine Growth Factor Rev. 2020;54:62-75. doi:10.1016/j.cytogfr.2020.06.001 
20. Liu T, Feng M, Wen Z, He Y, Lin W, Zhang M. Comparison of the characteristics of cytokine storm and immune response induced by SARS-CoV, MERS-CoV, and SARS-CoV-2 infections. J Inflamm Res. 2021;14:5475-5487. doi:10.2147/JIR.S329697

21. Dhar SK, Gujar S, Gujar S, Das M, Das M. IL-6 and IL-10 as predictors of disease severity in COVID-19 patients: results from meta-analysis and regression. Heliyon. 2021;7(2):e06155. doi:10.1016/j.heliyon.2021.e06155

22. Tang Y, Liu J, Zhang D, Xu Z, Ji J, Wen C. Cytokine storm in COVID-19: the current evidence and treatment strategies. Front Immunol. 2020;11. doi:10.3389/fimmu.2020.01708

23. Azkur AK, Akdis M, Azkur D, et al. Immune response to SARS-CoV-2 and mechanisms of immunopathological changes in COVID-19. Allergy. 2020;75(7):1564-1581. doi:10.1111/all.14364

24. Merad M, Martin JC. Pathological inflammation in patients with COVID-19: a key role for monocytes and macrophages. Nat Rev Immunol. 2020;20(6):355-362. doi:10.1038/s41577-020-0331-4

25. Chi Y, Ge Y, Wu B, et al. Serum cytokine and chemokine profile in relation to the severity of coronavirus disease 2019 in China. J Infect Dis. 2020;222(5):746-754. doi:10.1093/infdis/jiaa363

26. Zhang H, Wu T. CD4+T, CD8+T counts and severe COVID-19: a meta-analysis. J Infect. 2020;81(3):e82-e84. doi:10.1016/j.jinf.2020.06.036

27. Chen F, Zhang Y, Sucgang R, et al. Meta-analysis of host transcriptional responses to SARS-CoV-2 infection reveals their manifestation in human tumors. Sci Rep. 2021;11(1):2459. doi:10.1038/s41598-021-82221-4

28. Alnazawi M, Altaher A, Kandeel M. Comparative genomic analysis MERS CoV isolated from humans and camels with special reference to virus encoded helicase. Biol Pharm Bull. 2017;40(8):1289-1298. doi:10.1248/bpb.b17-00241

29. Raj VS, Mou H, Smits SL, et al. Dipeptidyl peptidase 4 is a functional receptor for the emerging human coronavirus-EMC. Nature. 2013;495 (7440):251-254. doi:10.1038/nature12005

30. Del Valle DM, Kim-Schulze S, Huang -H-H, et al. An inflammatory cytokine signature predicts COVID-19 severity and survival. Nat Med. 2020;26(10):1636-1643. doi:10.1038/s41591-020-1051-9

31. Chu H, Zhou J, Wong BH-Y, et al. Middle east respiratory syndrome coronavirus efficiently infects human primary T lymphocytes and activates the extrinsic and intrinsic apoptosis pathways. $J$ Infect Dis. 2016;213(6):904-914. doi:10.1093/infdis/jiv380

32. Lee S, Channappanavar R, Kanneganti T-D. Coronaviruses: innate immunity, inflammasome activation, inflammatory cell death, and cytokines. Trends Immunol. 2020;41(12):1083-1099. doi:10.1016/j.it.2020.10.005

33. de Sousa E, Ligeiro D, Lérias JR, et al. Mortality in COVID-19 disease patients: correlating the association of major histocompatibility complex (MHC) with severe acute respiratory syndrome 2 (SARS-CoV-2) variants. Int J Infect Dis. 2020;98:454-459. doi:10.1016/j. ijid.2020.07.016

34. Ahmed-Hassan H, Sisson B, Shukla RK, et al. Innate immune responses to highly pathogenic coronaviruses and other significant respiratory viral infections. Front Immunol. 2020;11. doi:10.3389/fimmu.2020.01979

35. Khalil BA, Elemam NM, Maghazachi AA. Chemokines and chemokine receptors during COVID-19 infection. Comput Struct Biotechnol J. 2021;19:976-988. doi:10.1016/j.csbj.2021.01.034

36. Weiss SR, Navas-Martin S. Coronavirus pathogenesis and the emerging pathogen severe acute respiratory syndrome coronavirus. Microbiol Mol Biol Rev. 2005;69(4):635-664. doi:10.1128/MMBR.69.4.635-664.2005

37. Kim Y-S, Aigerim A, Park U, et al. Sustained responses of neutralizing antibodies against middle east respiratory syndrome coronavirus (MERS-CoV) in recovered patients and their therapeutic applicability. Clin Infect Dis. 2021;73(3):e550-e558. doi:10.1093/cid/ciaa1345

38. Yi C, Sun X, Ye J, et al. Key residues of the receptor binding motif in the spike protein of SARS-CoV-2 that interact with ACE2 and neutralizing antibodies. Cell Mol Immunol. 2020;17(6):621-630. doi:10.1038/s41423-020-0458-z

39. Zhang Q, Xiang R, Huo S, et al. Molecular mechanism of interaction between SARS-CoV-2 and host cells and interventional therapy. Signal Transduct Target Ther. 2021;6(1):233. doi:10.1038/s41392-021-00653-w

40. Shulla A, Heald-Sargent T, Subramanya G, Zhao J, Perlman S, Gallagher T. A transmembrane serine protease is linked to the severe acute respiratory syndrome coronavirus receptor and activates virus entry. J Virol. 2011;85(2):873-882. doi:10.1128/JVI.02062-10

41. Huang Y, Yang C, Xu X, Xu W, Liu S. Structural and functional properties of SARS-CoV-2 spike protein: potential antivirus drug development for COVID-19. Acta Pharmacol Sin. 2020;41(9):1141-1149. doi:10.1038/s41401-020-0485-4

42. Pandey S, Kawai T, Akira S. Microbial sensing by toll-like receptors and intracellular nucleic acid sensors. Cold Spring Harb Perspect Biol. 2015;7(1):a016246. doi:10.1101/cshperspect.a016246

43. Catanzaro M, Fagiani F, Racchi M, Corsini E, Govoni S, Lanni C. Immune response in COVID-19: addressing a pharmacological challenge by targeting pathways triggered by SARS-CoV-2. Signal Transduct Target Ther. 2020;5(1):84. doi:10.1038/s41392-020-0191-1

44. Zenarruzabeitia O, Astarloa-Pando G, Terrén I, et al. T cell activation, highly armed cytotoxic cells and a shift in monocytes CD300 receptors expression is characteristic of patients with severe COVID-19. Front Immunol. 2021;12. doi:10.3389/fimmu.2021.655934

45. García LF. Immune response, inflammation, and the clinical spectrum of COVID-19. Front Immunol. 2020;11. doi:10.3389/fimmu.2020.01441

46. Alimardani V, Abolmaali SS, Tamaddon AM. Recent advances on nanotechnology-based strategies for prevention, diagnosis, and treatment of coronavirus infections. J Nanomater. 2021;2021:1-20. doi:10.1155/2021/9495126

47. Diaz RS, Vergara TRC. The COVID-19 second wave: a perspective to be explored. Brazilian J Infect Dis. 2021;25(1):101537. doi:10.1016/j. bjid.2020.101537

48. Shrotri M, van Schalkwyk MCI, Post N, et al. T cell response to SARS-CoV-2 infection in humans: a systematic review. PLoS One. 2021;16(1): e0245532. doi:10.1371/journal.pone.0245532

49. Pennock ND, White JT, Cross EW, Cheney EE, Tamburini BA, Kedl RM. T cell responses: naïve to memory and everything in between. Adv Physiol Educ. 2013;37(4):273-283. doi:10.1152/advan.00066.2013

50. Dan JM, Mateus J, Kato Y, et al. Immunological memory to SARS-CoV-2 assessed for up to 8 months after infection. Science (80-). 2021;371 (6529):eabf4063. doi:10.1126/science.abf4063

51. Ganji A, Farahani I, Khansarinejad B, Ghazavi A, Mosayebi G. Increased expression of CD8 marker on T-cells in COVID-19 patients. Blood Cells Mol Dis. 2020;83:102437. doi:10.1016/j.bcmd.2020.102437

52. Toor SM, Saleh R, Sasidharan Nair V, Taha RZ, Elkord E. T-cell responses and therapies against SARS-CoV-2 infection. Immunology. 2021 ; 162 (1):30-43. doi:10.1111/imm.13262

53. Farias de L, Fonseca EK, Strabelli DG, et al. Imaging findings in COVID-19 pneumonia. Clinics. 2020;75. doi:10.6061/clinics/2020/e2027 
54. Liao M, Liu Y, Yuan J, et al. Single-cell landscape of bronchoalveolar immune cells in patients with COVID-19. Nat Med. 2020;26(6):842-844. doi:10.1038/s41591-020-0901-9

55. Callahan V, Hawks S, Crawford MA, et al. The pro-inflammatory chemokines CXCL9, CXCL10 and CXCL11 are upregulated following SARS-CoV-2 infection in an AKT-dependent manner. Viruses. 2021;13(6):1062. doi:10.3390/v13061062

56. Kasuga Y, Zhu B, Jang K-J, Yoo J-S. Innate immune sensing of coronavirus and viral evasion strategies. Exp Mol Med. $2021 ; 53(5): 723-736$. doi:10.1038/s12276-021-00602-1

57. Amor S, Fernández Blanco L, Baker D. Innate immunity during SARS-CoV-2: evasion strategies and activation trigger hypoxia and vascular damage. Clin Exp Immunol. 2020;202(2):193-209. doi:10.1111/cei.13523

58. Chen Z, John Wherry E. T cell responses in patients with COVID-19. Nat Rev Immunol. 2020;20(9):529-536. doi:10.1038/s41577-020-0402-6

59. Zheng Y, Zhuang M-W, Han L, et al. Severe acute respiratory syndrome coronavirus 2 (SARS-CoV-2) membrane (M) protein inhibits type I and III interferon production by targeting RIG-I/MDA-5 signaling. Signal Transduct Target Ther. 2020;5(1):299. doi:10.1038/s41392-020-00438-7

60. Li J-Y, Liao C-H, Wang Q, et al. The ORF6, ORF8 and nucleocapsid proteins of SARS-CoV-2 inhibit type I interferon signaling pathway. Virus Res. 2020;286:198074. doi:10.1016/j.virusres.2020.198074

61. Schäfer A, Baric R. Epigenetic landscape during coronavirus infection. Pathogens. 2017;6(1):8. doi:10.3390/pathogens6010008

62. Mu J, Fang Y, Yang Q, et al. SARS-CoV-2 N protein antagonizes type I interferon signaling by suppressing phosphorylation and nuclear translocation of STAT1 and STAT2. Cell Discov. 2020;6(1):65. doi:10.1038/s41421-020-00208-3

63. Saifuddin N, Raziah AZ, Junizah AR. Carbon nanotubes: a review on structure and their interaction with proteins. $J$ Chem. 2013;2013:1-18. doi: $10.1155 / 2013 / 676815$

64. Yang W, Thordarson P, Gooding JJ, Ringer SP, Braet F. Carbon nanotubes for biological and biomedical applications. Nanotechnology. 2007;18 (41):412001. doi:10.1088/0957-4484/18/41/412001

65. Zhang M, Yang M, Morimoto T, et al. Size-dependent cell uptake of carbon nanotubes by macrophages: a comparative and quantitative study. Carbon N Y. 2018;127:93-101. doi:10.1016/j.carbon.2017.10.085

66. Dong J. Signaling pathways implicated in carbon nanotube-induced lung inflammation. Front Immunol. 2020;11. doi:10.3389/ fimmu.2020.552613

67. Orecchioni M, Bedognetti D, Sgarrella F, Marincola FM, Bianco A, Delogu L. Impact of carbon nanotubes and graphene on immune cells. $J$ Transl Med. 2014;12(1):138. doi:10.1186/1479-5876-12-138

68. Singh S, Vardharajula S, Tiwari P, et al. Functionalized carbon nanotubes: biomedical applications. Int J Nanomedicine. 2012;5361. doi:10.2147/IJN.S35832

69. Thakur N, Thakur S, Chatterjee S, Das J, Sil PC. Nanoparticles as smart carriers for enhanced cancer immunotherapy. Front Chem. 2020;8. doi:10.3389/fchem.2020.597806

70. Huang Y, Zeng J. Recent development and applications of nanomaterials for cancer immunotherapy. Nanotechnol Rev. 2020;9(1):367-384. doi:10.1515/ntrev-2020-0027

71. Zhu M, Wang R, Nie G. Applications of nanomaterials as vaccine adjuvants. Hum Vaccin Immunother. 2014;10(9):2761-2774. doi:10.4161/ hv. 29589

72. Tîlmaciu C-M, Morris MC. Carbon nanotube biosensors. Front Chem. 2015;3. doi:10.3389/fchem.2015.00059

73. Nagaraju K, Reddy R, Reddy N. A review on protein functionalized carbon nanotubes. J Appl Biomater Funct Mater. 2015;13(4). doi:10.5301/ jabfm.5000231

74. Dong J, Ma Q. Type 2 immune mechanisms in carbon nanotube-induced lung fibrosis. Front Immunol. 2018;9. doi:10.3389/fimmu.2018.01120

75. Brown JM, Bai W, Raghavendra A, Podila R. Defect density in multiwalled carbon nanotubes influences ovalbumin adsorption and promotes macrophage activation and CD4+ T-cell proliferation. Int J Nanomedicine. 2016;11:4357-4371. doi:10.2147/IJN.S111029

76. Murphy FA, Schinwald A, Poland CA, Donaldson K. The mechanism of pleural inflammation by long carbon nanotubes: interaction of long fibres with macrophages stimulates them to amplify pro-inflammatory responses in mesothelial cells. Part Fibre Toxicol. 2012;9(1):8. doi:10.1186/1743-8977-9-8

77. Parra J, Abad-Somovilla A, Mercader JV, Taton TA, Abad-Fuentes A. Carbon nanotube-protein carriers enhance size-dependent self-adjuvant antibody response to haptens. J Control Release. 2013;170(2):242-251. doi:10.1016/j.jconrel.2013.05.019

78. Pondman KM, Salvador-Morales C, Paudyal B, Sim RB, Kishore U. Interactions of the innate immune system with carbon nanotubes Nanoscale Horizons. 2017;2(4):174-186. doi:10.1039/C6NH00227G

79. Maruyama K, Haniu H, Saito N, et al. Endocytosis of multiwalled carbon nanotubes in bronchial epithelial and mesothelial cells. Biomed Res Int. 2015;2015:1-9. doi:10.1155/2015/793186

80. Zhou L, Forman HJ, Ge Y, Lunec J. Multi-walled carbon nanotubes: a cytotoxicity study in relation to functionalization, dose and dispersion. Toxicol Vitr. 2017;42:292-298. doi:10.1016/j.tiv.2017.04.027

81. Hamad I, Christy hunter A, Rutt KJ, Liu Z, Dai H, Moein Moghimi S. Complement activation by PEGylated single-walled carbon nanotubes is independent of C1q and alternative pathway turnover. Mol Immunol. 2008;45(14):3797-3803. doi:10.1016/j.molimm.2008.05.020

82. Allegri M, Perivoliotis DK, Bianchi MG, et al. Toxicity determinants of multi-walled carbon nanotubes: the relationship between functionalization and agglomeration. Toxicol Rep. 2016;3:230-243. doi:10.1016/j.toxrep.2016.01.011

83. Carty M, Guy C, Bowie AG. Detection of Viral Infections by Innate Immunity. Biochem Pharmacol. 2021;183:114316. doi:10.1016/j. bcp. 2020.114316

84. Pal M, Berhanu G, Desalegn C, Kandi V. Severe acute respiratory syndrome coronavirus-2 (SARS-CoV-2): an update. Cureus. 2020. doi:10.7759/cureus. 7423

85. Le Bert N, Tan AT, Kunasegaran K, et al. SARS-CoV-2-specific T cell immunity in cases of COVID-19 and SARS, and uninfected controls Nature. 2020;584(7821):457-462. doi:10.1038/s41586-020-2550-Z

86. Zhang Z, Wang B, Wan B, Yu L, Huang Q. Molecular dynamics study of carbon nanotube as a potential dual-functional inhibitor of HIV-1 integrase. Biochem Biophys Res Commun. 2013;436(4):650-654. doi:10.1016/j.bbrc.2013.06.009

87. Prompetchara E, Ketloy C, Palaga T. Immune responses in COVID-19 and potential vaccines: lessons learned from SARS and MERS epidemic. Asian Pacific J Allerg Immunol. 2020. doi:10.12932/AP-200220-0772 
88. Chen B, Tian E-K, He B, et al. Overview of lethal human coronaviruses. Signal Transduct Target Ther. 2020;5(1):89. doi:10.1038/s41392-0200190-2

89. Khang D, Lee YK, Choi E-J, Webster TJ, Kim S-H. Effect of the protein Corona on nanoparticles for modulating cytotoxicity and immunotoxicity. Int J Nanomedicine. 2014;97. doi:10.2147/IJN.S72998

90. Aldinucci A, Turco A, Biagioli T, et al. Carbon nanotube scaffolds instruct human dendritic cells: modulating immune responses by contacts at the nanoscale. Nano Lett. 2013;13(12):6098-6105. doi:10.1021/n1403396e

91. Yehia HN, Draper RK, Mikoryak C, et al. Single-walled carbon nanotube interactions with HeLa cells. J Nanobiotechnology. 2007;5(1):8. doi:10.1186/1477-3155-5-8

92. Sierra S, Dávila M, Lowenstein PR, Domingo E. Response of foot-and-mouth disease virus to increased mutagenesis: influence of viral load and fitness in loss of infectivity. J Virol. 2000;74(18):8316-8323. doi:10.1128/jvi.74.18.8316-8323.2000

93. Palomäki J, Välimäki E, Sund J, et al. Long, needle-like carbon nanotubes and asbestos activate the NLRP3 inflammasome through a similar mechanism. ACS Nano. 2011;5(9):6861-6870. doi:10.1021/nn200595c

94. Fadel TR, Steenblock ER, Stern E, et al. Enhanced cellular activation with single walled carbon nanotube bundles presenting antibody stimuli. Nano Lett. 2008;8(7):2070-2076. doi:10.1021/n1080332i

95. Goldsmith BR, Brisson D, Lerner M. Researchers Attach Lyme Disease Antibodies to Nanotubes, Paving Way for Diagnostic Device. University of Pennsylvania; 2013:1-3.

96. Hassan HA, Diebold SS, Smyth LA, Walters AA, Lombardi G, Al-Jamal KT. Application of carbon nanotubes in cancer vaccines: achievements, challenges and chances. J Control Release. 2019;297:79-90. doi:10.1016/j.jconrel.2019.01.017

97. Elhissi AMA, Ahmed W, Hassan IU, Dhanak VR, D’Emanuele A. Carbon nanotubes in cancer therapy and drug delivery. J Drug Deliv. 2012;2012:1-10. doi:10.1155/2012/837327

98. Son KH, Hong JH, Lee JW. Carbon nanotubes as cancer therapeutic carriers and mediators. Int J Nanomedicine. 2016 ; 11:5163-5185. doi:10.2147/IJN.S112660

99. Adesina SK, Akala EO. Nanotechnology approaches for the delivery of exogenous siRNA for HIV therapy. Mol Pharm. 2015;12 (12):4175-4187. doi:10.1021/acs.molpharmaceut.5b00335

100. Kirkpatrick DL, Weiss M, Naumov A, Bartholomeusz G, Weisman RB, Gliko O. Carbon nanotubes: solution for the therapeutic delivery of siRNA? Materials (Basel). 2012;5(12):278-301. doi:10.3390/ma5020278

101. Karchemski F, Zucker D, Barenholz Y, Regev O. Carbon nanotubes-liposomes conjugate as a platform for drug delivery into cells. J Control Release. 2012;160(2):339-345. doi:10.1016/j.jconrel.2011.12.037

102. Hassan HA, Smyth L, Wang JT-W, et al. Dual stimulation of antigen presenting cells using carbon nanotube-based vaccine delivery system for cancer immunotherapy. Biomaterials. 2016;104:310-322. doi:10.1016/j.biomaterials.2016.07.005

103. Wang X, Ren J, Qu X. Targeted RNA interference of cyclin A2 mediated by functionalized single-walled carbon nanotubes induces proliferation arrest and apoptosis in chronic myelogenous leukemia K562 cells. ChemMedChem. 2008;3(6):940-945. doi:10.1002/ cmdc. 200700329

104. Patra JK, Das G, Fraceto LF, et al. Nano based drug delivery systems: recent developments and future prospects. J Nanobiotechnology. $2018 ; 16$ (1):71. doi:10.1186/s12951-018-0392-8

105. Hassan HA, Smyth L, Rubio N, et al. Carbon nanotubes' surface chemistry determines their potency as vaccine nanocarriers in vitro and in vivo. J Control Release. 2016;225:205-216. doi:10.1016/j.jconrel.2016.01.030

106. Tkach AV, Shurin GV, Shurin MR, et al. Direct effects of carbon nanotubes on dendritic cells induce immune suppression upon pulmonary exposure. ACS Nano. 2011;5(7):5755-5762. doi:10.1021/nn2014479

107. Lauster D, Klenk S, Ludwig K, et al. Phage capsid nanoparticles with defined ligand arrangement block influenza virus entry. Nat Nanotechnol. 2020;15(5):373-379. doi:10.1038/s41565-020-0660-2

108. Vijayan M, Uthaman P. Recent advances in nanovaccines using biomimetic immunomodulatory materials. Pharmaceutics. 2019;11(10):534. doi:10.3390/pharmaceutics11100534

109. Meher BR, Wang Y. Binding of single walled carbon nanotube to WT and mutant HIV-1 proteases: analysis of flap dynamics and binding mechanism. J Mol Graph Model. 2012;38:430-445. doi:10.1016/j.jmgm.2012.10.001

110. Pereyra F, Heckerman D, Carlson JM, et al. HIV control is mediated in part by CD8+ T-cell targeting of specific epitopes. $J$ Virol. 2014;88 (22):12937-12948. doi:10.1128/JVI.01004-14

111. Hunt PW. Th17, gut, and HIV: therapeutic implications. Curr Opin HIV AIDS. 2010;5(2):189-193. doi:10.1097/COH.0b013e32833647d9

112. Vela Ramirez JE, Roychoudhury R, Habte HH, Cho MW, Pohl NLB, Narasimhan B. Carbohydrate-functionalized nanovaccines preserve HIV-1 antigen stability and activate antigen presenting cells. J Biomater Sci Polym Ed. 2014;25(13):1387-1406. doi:10.1080/09205063.2014.940243

113. Nagy LH, Grishina I, Macal M, et al. Chronic HIV infection enhances the responsiveness of antigen presenting cells to commensal lactobacillus. PLoS One. 2013;8:8. doi:10.1371/journal.pone.0072789

114. Pantarotto D, Partidos CD, Hoebeke J, et al. Immunization with peptide-functionalized carbon nanotubes enhances virus-specific neutralizing antibody responses. Chem Biol. 2003;10(10):961-966. doi:10.1016/j.chembiol.2003.09.011

115. Villa $\mathrm{CH}$, Dao T, Ahearn I, et al. Single-walled carbon nanotubes deliver peptide antigen into dendritic cells and enhance IgG responses to tumor-associated antigens. ACS Nano. 2011;5(7):5300-5311. doi:10.1021/nn200182x

116. Feng M, Bell DR, Zhou R. Propensity of a single-walled carbon nanotube-peptide to mimic a KK10 peptide in an HLA-TCR complex. J Chem Phys. 2017;147(22):225101. doi:10.1063/1.4996374

117. Olsen LR, Zhang GL, Keskin DB, Reinherz EL, Brusic V. Conservation analysis of dengue virus t-cell epitope-based vaccine candidates using peptide block entropy. Front Immunol. 2011;2:(DEC):1-15. doi:10.3389/fimmu.2011.00069

118. Versiani AF, Astigarraga RG, Rocha ESO, et al. Multi-walled carbon nanotubes functionalized with recombinant Dengue virus 3 envelope proteins induce significant and specific immune responses in mice. J Nanobiotechnology. 2017;15(1):26. doi:10.1186/s12951-017-0259-4

119. Ménard-Moyon C, Kostarelos K, Prato M, Bianco A. Functionalized carbon nanotubes for probing and modulating molecular functions. Chem Biol. 2010;17(2):107-115. doi:10.1016/j.chembiol.2010.01.009

120. Zhao Z, Zhang C, Jia Y-J, et al. Immersion vaccination of Mandarin fish Siniperca chuatsi against infectious spleen and kidney necrosis virus with a SWCNTs-based subunit vaccine. Fish Shellfish Immunol. 2019;92:133-140. doi:10.1016/j.fsi.2019.06.001 
121. Zhao Z, Zhang C, Lin Q, et al. Single-walled carbon nanotubes as delivery vehicles enhance the immunoprotective effect of an immersion DNA vaccine against infectious spleen and kidney necrosis virus in mandarin fish. Fish Shellfish Immunol. 2020;97:432-439. doi:10.1016/j. fsi.2019.12.072

122. Jia Y-J, Guo Z-R, Ma R, et al. Immune efficacy of carbon nanotubes recombinant subunit vaccine against largemouth bass ulcerative syndrome virus. Fish Shellfish Immunol. 2020;100:317-323. doi:10.1016/j.fsi.2020.03.025

123. Hu F, Li Y, Wang Q, et al. Carbon nanotube-based DNA vaccine against koi herpesvirus given by intramuscular injection. Fish Shellfish Immunol. 2020;98:810-818. doi:10.1016/j.fsi.2019.11.035

124. Sano M, Ito T, Kurita J, et al. First detection of Koi Herpesvirus in cultured common Carp Cyprinus carpio in Japan. Fish Pathol. 2004;39 (3):165-167. doi:10.3147/jsfp.39.165

125. Zhu B, Liu G-L, Gong Y-X, Ling F, Song L-S, Wang G-X. Single-walled carbon nanotubes as candidate recombinant subunit vaccine carrier for immunization of grass carp against grass carp reovirus. Fish Shellfish Immunol. 2014;41(2):279-293. doi:10.1016/j.fsi.2014.09.014

126. Qiu D-K, Jia Y-J, Gong Y-M, Zheng -Y-Y, Wang G-X, Zhu B. Optimizing the immunization procedure of single-walled carbon nanotubes based vaccine against grass carp reovirus for grass carp. Aquaculture. 2021;533:736152. doi:10.1016/j.aquaculture.2020.736152

127. Su H, Su J. Cyprinid viral diseases and vaccine development. Fish Shellfish Immunol. 2018;83:84-95. doi:10.1016/j.fsi.2018.09.003

128. Wang Y, Liu G-L, Li D-L, Ling F, Zhu B, Wang G-X. The protective immunity against grass carp reovirus in grass carp induced by a DNA vaccination using single-walled carbon nanotubes as delivery vehicles. Fish Shellfish Immunol. 2015;47(2):732-742. doi:10.1016/j. fsi.2015.10.029

129. Costa PM, Bourgognon M, Wang JT-W, Al-Jamal KT. Functionalised carbon nanotubes: from intracellular uptake and cell-related toxicity to systemic brain delivery. J Control Release. 2016;241:200-219. doi:10.1016/j.jconrel.2016.09.033

130. McDevitt MR, Chattopadhyay D, Kappel BJ, et al. Tumor targeting with antibody-functionalized, radiolabeled carbon nanotubes. J Nucl Med. 2007;48(7):1180-1189. doi:10.2967/jnumed.106.039131

131. Meng J, Meng J, Duan J, et al. Carbon nanotubes conjugated to tumor lysate protein enhance the efficacy of an antitumor immunotherapy. Small. 2008;4(9):1364-1370. doi:10.1002/smll.200701059

132. Gannon CJ, Cherukuri P, Yakobson BI, et al. Carbon nanotube-enhanced thermal destruction of cancer cells in a noninvasive radiofrequency field. Cancer. 2007;110(12):2654-2665. doi:10.1002/cncr.23155

133. Xu H, Meng J, Kong H. What are carbon nanotubes' roles in anti-tumor therapies? Sci China Chem. 2010;53(11):2250-2256. doi:10.1007/ s11426-010-4117-6

134. Battigelli A, Ménard-Moyon C, Bianco A. Carbon nanomaterials as new tools for immunotherapeutic applications. $J$ Mater Chem B. 2014;2 (37):6144-6156. doi:10.1039/C4TB00563E

135. Dumortier H, Lacotte S, Pastorin G, et al. Functionalized carbon nanotubes are non-cytotoxic and preserve the functionality of primary immune cells. Nano Lett. 2006;6(7):1522-1528. doi:10.1021/n1061160x

136. Yeh J-M, Huang K-Y, Lin S-Y, Wu -Y-Y, Huang -C-C, Liou S-J. Noncovalent interaction between gold nanoparticles and multiwalled carbon nanotubes via an intermediatory. J Nanotechnol. 2009;2009:1-7. doi:10.1155/2009/217469

137. Hu X, Zhang Y, Ding T, Liu J, Zhao H. Multifunctional gold nanoparticles: a novel nanomaterial for various medical applications and biological activities. Front Bioeng Biotechnol. 2020;8. doi:10.3389/fbioe.2020.00990

138. Rance GA, Khlobystov AN. Interactions of carbon nanotubes and gold nanoparticles: the effects of solvent dielectric constant and temperature on controlled assembly of superstructures. Dalt Trans. 2014;43(20):7400. doi:10.1039/c3dt53372g

139. Kim H, Park M, Hwang J, et al. Development of label-free colorimetric assay for MERS-CoV using gold nanoparticles. ACS Sensors. 2019;4 (5):1306-1312. doi:10.1021/acssensors.9b00175

140. Pramanik A, Gao Y, Patibandla S, et al. The rapid diagnosis and effective inhibition of coronavirus using spike antibody attached gold nanoparticles. Nanoscale Adv. 2021;3(6):1588-1596. doi:10.1039/D0NA01007C

141. Mehranfar A, Izadyar M. Theoretical design of functionalized gold nanoparticles as antiviral agents against severe acute respiratory syndrome coronavirus 2 (SARS-CoV-2). J Phys Chem Lett. 2020;11(24):10284-10289. doi:10.1021/acs.jpclett.0c02677

142. Tharayil A, Rajakumari R, Kumar A, Choudhary MD, Palit P, Thomas S. New insights into application of nanoparticles in the diagnosis and screening of novel coronavirus (SARS-CoV-2). Emergent Mater. 2021;4(1):101-117. doi:10.1007/s42247-021-00182-w

143. Paradowska E, Studzińska M, Jabłońska A, et al. Antiviral effect of nonfunctionalized gold nanoparticles against herpes simplex virus type-1 (HSV-1) and possible contribution of near-field interaction mechanism. Molecules. 2021;26(19):5960. doi:10.3390/molecules26195960

144. Lew TTS, Aung KMM, Ow SY, et al. Epitope-functionalized gold nanoparticles for rapid and selective detection of SARS-CoV-2 IgG antibodies. ACS Nano. 2021;15(7):12286-12297. doi:10.1021/acsnano.1c04091

145. Medhi R, Srinoi P, Ngo N, Tran H-V, Lee TR. Nanoparticle-Based Strategies to Combat COVID-19. ACS Appl Nano Mater. 2020;3 (9):8557-8580. doi:10.1021/acsanm.0c01978

146. Galdiero S, Falanga A, Vitiello M, Cantisani M, Marra V, Galdiero M. Silver nanoparticles as potential antiviral agents. Molecules. 2011;16 (10):8894-8918. doi:10.3390/molecules16108894

147. Lee B, Lee MJ, Yun SJ, Kim K, Choi I-H, Park S. Silver nanoparticles induce reactive oxygen species-mediated cell cycle delay and synergistic cytotoxicity with 3-bromopyruvate in Candida albicans, but not in Saccharomyces cerevisiae. Int J Nanomedicine. 2019;14:4801-4816. doi:10.2147/IJN.S205736

148. Quinteros MA, Cano Aristizábal V, Dalmasso PR, Paraje MG, Páez PL. Oxidative stress generation of silver nanoparticles in three bacterial genera and its relationship with the antimicrobial activity. Toxicol Vitr. 2016;36:216-223. doi:10.1016/j.tiv.2016.08.007

149. Khodashenas B, Ghorbani HR. Synthesis of silver nanoparticles with different shapes. Arab J Chem. 2019;12(8):1823-1838. doi:10.1016/j. arabjc.2014.12.014

150. Allawadhi P, Singh V, Khurana A, et al. Silver nanoparticle based multifunctional approach for combating COVID-19. Sensors Int. 2021;2:100101. doi:10.1016/j.sintl.2021.100101

151. Parnsamut C, Brimson S. Effects of silver nanoparticles and gold nanoparticles on IL-2, IL-6, and TNF- $\alpha$ production via MAPK pathway in leukemic cell lines. Genet Mol Res. 2015;14(2):3650-3668. doi:10.4238/2015.April.17.15

152. Borowik A, Butowska K, Konkel K, et al. The impact of surface functionalization on the biophysical properties of silver nanoparticles. Nanomaterials. 2019;9(7):973. doi:10.3390/nano9070973 
153. Di Pietro P, Strano G, Zuccarello L, Satriano C. Gold and silver nanoparticles for applications in theranostics. Curr Top Med Chem. 2016 ; 16 (27):3069-3102. doi:10.2174/1568026616666160715163346

154. Liu Y, Zhang D, Alocilja EC, Chakrabartty S. Biomolecules detection using a silver-enhanced gold nanoparticle-based biochip. Nanoscale Res Lett. 2010;5(3):533-538. doi:10.1007/s11671-010-9542-0

155. Pilaquinga F, Morey J, Torres M, Seqqat R, Piña de Las N. Silver nanoparticles as a potential treatment against SARS-CoV -2: a review. WIREs Nanomed Nanobiotechnol. 2021;13(5). doi:10.1002/wnan.1707

156. Bruna T, Maldonado-Bravo F, Jara P, Caro N. Silver nanoparticles and their antibacterial applications. Int J Mol Sci. $2021 ; 22(13)$ :7202. doi:10.3390/ijms22137202

157. Chue-Gonçalves M, Pereira GN, Faccin-Galhardi LC, Kobayashi RKT, Nakazato G. Metal nanoparticles against viruses: possibilities to fight SARS-CoV-2. Nanomaterials. 2021;11(11):3118. doi:10.3390/nano11113118

158. Niemiec SM, Hilton SA, Wallbank A, et al. Lung function improves after delayed treatment with CNP-miR146a following acute lung injury. Nanomed Nanotechnol Biol Med. 2021;102498. doi:10.1016/j.nano.2021.102498

159. Allawadhi P, Khurana A, Allwadhi S, Joshi K, Packirisamy G, Bharani KK. Nanoceria as a possible agent for the management of COVID-19. Nano Today. 2020;35:100982. doi:10.1016/j.nantod.2020.100982

160. Choudhary S, Sharma K, Silakari O. The interplay between inflammatory pathways and COVID-19: a critical review on pathogenesis and therapeutic options. Microb Pathog. 2021;150:104673. doi:10.1016/j.micpath.2020.104673

161. Khurana A, Anchi P, Allawadhi P, et al. Superoxide dismutase mimetic nanoceria restrains cerulein induced acute pancreatitis. Nanomedicine. 2019;14(14):1805-1825. doi:10.2217/nnm-2018-0318

162. Khurana I, Allawadhi P, Khurana A, et al. Can bilirubin nanomedicine become a hope for the management of COVID-19? Med Hypotheses. 2021;149:110534. doi:10.1016/j.mehy.2021.110534

163. Rasmi Y, Saloua KS, Nemati M, Choi JR. Recent progress in nanotechnology for COVID-19 prevention, diagnostics and treatment. Nanomaterials. 2021;11(7):1788. doi:10.3390/nano11071788

164. Niemiec SM, Hilton SA, Wallbank A, et al. Cerium oxide nanoparticle delivery of microRNA-146a for local treatment of acute lung injury. Nanomed Nanotechnol Biol Med. 2021;34:102388. doi:10.1016/j.nano.2021.102388

165. Jagaran K, Singh M. Nanomedicine for COVID-19: potential of Copper Nanoparticles. Biointerface Res Appl Chem. $2020 ; 11(3): 10716-10728$. doi:10.33263/BRIAC113.1071610728

166. Wang ZY, He N, Wang YJ, Zhang J. Effects of copper on organisms: a review. Adv Mater Res. 2013;726-731:340-343. doi:10.4028/www. scientific.net/AMR.726-731.340

167. Tortella GR, Pieretti JC, Rubilar O, et al. Silver, copper and copper oxide nanoparticles in the fight against human viruses: progress and perspectives. Crit Rev Biotechnol. 2021;1-19. doi:10.1080/07388551.2021.1939260

168. Tyavambiza C, Elbagory AM, Madiehe AM, Meyer M, Meyer S. The antimicrobial and anti-inflammatory effects of silver nanoparticles synthesised from cotyledon orbiculata aqueous extract. Nanomaterials. 2021;11(5):1343. doi:10.3390/nano11051343

169. Bondarenko OM, Sihtmäe M, Kuzmičiova J, Ragelienè L, Kahru A, Daugelavičius R. Plasma membrane is the target of rapid antibacterial action of silver nanoparticles in Escherichia coli and Pseudomonas aeruginosa. Int J Nanomedicine. 2018;13:6779-6790. doi:10.2147/IJN. S177163

170. Govind V, Bharadwaj S, Sai Ganesh MR, et al. Antiviral properties of copper and its alloys to inactivate covid-19 virus: a review. BioMetals. 2021;34(6):1217-1235. doi:10.1007/s10534-021-00339-4

171. Peng Z, Liu X, Zhang W, et al. Advances in the application, toxicity and degradation of carbon nanomaterials in environment: a review. Environ Int. 2020;134:105298. doi:10.1016/j.envint.2019.105298

172. Vlasova II, Vakhrusheva TV, Sokolov AV, et al. PEGylated single-walled carbon nanotubes activate neutrophils to increase production of hypochlorous acid, the oxidant capable of degrading nanotubes. Toxicol Appl Pharmacol. 2012;264(1):131-142. doi:10.1016/j. taap.2012.07.027

173. Shvedova AA, Pietroiusti A, Fadeel B, Kagan VE. Mechanisms of carbon nanotube-induced toxicity: focus on oxidative stress. Toxicol Appl Pharmacol. 2012;261(2):121-133. doi:10.1016/j.taap.2012.03.023

174. Sobajima A, Haniu H, Nomura H, et al. Organ accumulation and carcinogenicity of highly dispersed multi-walled carbon nanotubes administered intravenously in transgenic rasH2 mice. Int J Nanomedicine. 2019;14:6465-6480. doi:10.2147/IJN.S208129

175. Magrez A, Kasas S, Salicio V, et al. Cellular toxicity of carbon-based nanomaterials. Nano Lett. 2006;6(6):1121-1125. doi:10.1021/nl060162e

176. Vlasova II, Kapralov AA, Michael ZP, et al. Enzymatic oxidative biodegradation of nanoparticles: mechanisms, significance and applications. Toxicol Appl Pharmacol. 2016;299:58-69. doi:10.1016/j.taap.2016.01.002

177. Allen BL, Kichambare PD, Gou P, et al. Biodegradation of single-walled carbon nanotubes through enzymatic catalysis. Nano Lett. 2008;8 (11):3899-3903. doi:10.1021/nl802315h

178. Kotchey GP, Zhao Y, Kagan VE, Star A. Peroxidase-mediated biodegradation of carbon nanotubes in vitro and in vivo. Adv Drug Deliv Rev. 2013;65(15):1921-1932. doi:10.1016/j.addr.2013.07.007

179. Kotchey GP, Gaugler JA, Kapralov AA, Kagan VE, Star A. Effect of antioxidants on enzyme-catalysed biodegradation of carbon nanotubes. J Mater Chem B. 2013;1(3):302-309. doi:10.1039/C2TB00047D

180. Yang M, Zhang M. Biodegradation of carbon nanotubes by macrophages. Front Mater. 2019;6. doi:10.3389/fmats.2019.00225

181. Yang M, Zhang M, Nakajima H, Yudasaka M, Iijima S, Okazaki T. Time-dependent degradation of carbon nanotubes correlates with decreased reactive oxygen species generation in macrophages. Int J Nanomedicine. 2019;14:2797-2807. doi:10.2147/IJN.S199187

182. Hou J, Wan B, Yang Y, Ren X-M, Guo L-H, Liu J-F. Biodegradation of single-walled carbon nanotubes in macrophages through respiratory burst modulation. Int J Mol Sci. 2016;17(3):409. doi:10.3390/ijms17030409

183. Zhu W, von Dem Bussche A, Yi X, et al. Nanomechanical mechanism for lipid bilayer damage induced by carbon nanotubes confined in intracellular vesicles. Proc Natl Acad Sci. 2016;113(44):12374-12379. doi:10.1073/pnas.1605030113

184. Khurana A, Allawadhi P, Khurana I, et al. Role of nanotechnology behind the success of mRNA vaccines for COVID-19. Nano Today. 2021;38:101142. doi:10.1016/j.nantod.2021.101142

185. Fraix A, Kandoth N, Manet I, et al. An engineered nanoplatform for bimodal anticancer phototherapy with dual-color fluorescence detection of sensitizers. Chem Commun (Camb). 2013;49(40):4459-4461. doi:10.1039/c3cc40714d 
186. Gelperina S, Kisich K, Iseman MD, Heifets L. The potential advantages of nanoparticle drug delivery systems in chemotherapy of tuberculosis. Am J Respir Crit Care Med. 2005;172(12):1487-1490. doi:10.1164/rccm.200504-613PP

187. Tartof SY, Slezak JM, Fischer H, et al. Effectiveness of mRNA BNT162b2 COVID-19 vaccine up to 6 months in a large integrated health system in the USA: a retrospective cohort study. Lancet. 2021;398(10309):1407-1416. doi:10.1016/S0140-6736(21)02183-8

188. Jazayeri SD, Lim HX, Shameli K, Yeap SK, Poh CL. Nano and microparticles as potential oral vaccine carriers and adjuvants against infectious diseases. Front Pharmacol. 2021;12. doi:10.3389/fphar.2021.682286

189. Nature Editorials. Nanotechnology versus coronavirus. Nat Nanotechnol. 2020;15(8):617. doi:10.1038/s41565-020-0757-7

190. Fadel TR, Fahmy TM. Immunotherapy applications of carbon nanotubes: from design to safe applications. Trends Biotechnol. 2014;32 (4):198-209. doi:10.1016/j.tibtech.2014.02.005

191. Kim H, Kim EH, Kwak G, Chi S-G, Kim SH, Yang Y. Exosomes: cell-derived nanoplatforms for the delivery of cancer therapeutics. Int J Mol Sci. 2020;22(1):14. doi:10.3390/ijms22010014

192. Heo MB, Lim YT. Programmed nanoparticles for combined immunomodulation, antigen presentation and tracking of immunotherapeutic cells. Biomaterials. 2014;35(1):590-600. doi:10.1016/j.biomaterials.2013.10.009

193. Kraegeloh A, Suarez-Merino B, Sluijters T, Micheletti C. Implementation of safe-by-design for nanomaterial development and safe innovation: why we need a comprehensive approach. Nanomaterials. 2018;8(4):239. doi:10.3390/nano8040239

194. Rai M, Bonde S, Yadav A, et al. Nanotechnology as a shield against COVID-19: current advancement and limitations. Viruses. 2021;13 (7):1224. doi:10.3390/v13071224

195. Himaja AL, Karthik PS, Singh SP. Carbon dots: the newest member of the carbon nanomaterials family. Chem Rec. 2015;15(3):595-615. doi:10.1002/tcr.201402090

196. Atabaev T. Doped carbon dots for sensing and bioimaging applications: a minireview. Nanomaterials. 2018;8(5):342. doi:10.3390/nano8050342

197. Kotta S, Aldawsari HM, Badr-Eldin SM, et al. Exploring the Potential of Carbon Dots to Combat COVID-19. Front Mol Biosci. $2020 ; 7$. doi:10.3389/fmolb.2020.616575

198. Serrano-Aroca Á, Takayama K, Tunón-Molina A, et al. Carbon-based nanomaterials: promising antiviral agents to combat COVID-19 in the microbial-resistant era. ACS Nano. 2021;15(5):8069-8086. doi:10.1021/acsnano.1c00629

199. Liang L, Ahamed A, Ge L, Fu X, Lisak G. Advances in antiviral material development. Chempluschem. 2020;85(9):2105-2128. doi:10.1002/ cplu.202000460

200. Liu H, Chen J, Qiao S, Zhang W. Carbon-based nanomaterials for bone and cartilage regeneration: a review. ACS Biomater Sci Eng. 2021;7 (10):4718-4735. doi:10.1021/acsbiomaterials.1c00759

201. Ehtesabi H. Application of carbon nanomaterials in human virus detection. J Sci Adv Mater Devices. 2020;5(4):436-450. doi:10.1016/j. jsamd.2020.09.005

202. Innocenzi P, Stagi L. Carbon-based antiviral nanomaterials: graphene, C-dots, and fullerenes. A perspective. Chem Sci. 2020;11(26):6606-6622. doi:10.1039/D0SC02658A

203. Chen M, Sun Y, Liang J, et al. Understanding the influence of carbon nanomaterials on microbial communities. Environ Int. 2019;126:690-698. doi:10.1016/j.envint.2019.02.005

204. Wang F-T, Wang L-N, Xu J, Huang K-J, Wu X. Synthesis and modification of carbon dots for advanced biosensing application. Analyst. 2021;146(14):4418-4435. doi:10.1039/D1AN00466B

205. Kalkal A, Allawadhi P, Pradhan R, Khurana A, Bharani KK, Packirisamy G. Allium sativum derived carbon dots as a potential theranostic agent to combat the COVID-19 crisis. Sensors Int. 2021;2:100102. doi:10.1016/j.sint1.2021.100102

206. Ahmadian-Fard-Fini S, Ghanbari D, Salavati-Niasari M. Photoluminescence carbon dot as a sensor for detecting of Pseudomonas aeruginosa bacteria: hydrothermal synthesis of magnetic hollow NiFe2O4-carbon dots nanocomposite material. Compos Part B Eng. 2019;161:564-577. doi:10.1016/j.compositesb.2018.12.131

207. Kuri-Cervantes L, Pampena MB, Meng W, et al. Comprehensive mapping of immune perturbations associated with severe COVID-19. Sci Immunol. 2020;5(49):eabd7114. doi:10.1126/sciimmunol.abd7114

208. Liang Y, Wang ML, Chien CS, et al.Highlight of immune pathogenic response and hematopathologic effect in SARS-CoV, MERS-CoV, and SARS-Cov-2 infection. Front Immunol. 2020;11:1022.

International Journal of Nanomedicine

Dovepress

\section{Publish your work in this journal}

The International Journal of Nanomedicine is an international, peer-reviewed journal focusing on the application of nanotechnology in diagnostics, therapeutics, and drug delivery systems throughout the biomedical field. This journal is indexed on PubMed Central, MedLine, CAS, SciSearch ${ }^{\mathbb{B}}$, Current Contents ${ }^{\mathbb{B}} /$ Clinical Medicine, Journal Citation Reports/Science Edition, EMBase, Scopus and the Elsevier Bibliographic databases. The manuscript management system is completely online and includes a very quick and fair peer-review system, which is all easy to use. Visit http:// www.dovepress.com/testimonials.php to read real quotes from published authors.

Submit your manuscript here: https://www.dovepress.com/international-journal-of-nanomedicine-journal 